\title{
Epigenome-Wide Associations Between Observed Maternal Sensitivity and Offspring DNA Methylation: A Population-Based Prospective Study in Children
}

\section{SELF-ARCHIVING VERSION}

Lorenza Dall'Aglio ${ }^{1,2}$, MSc., Jolien Rijlaarsdam ${ }^{1,2^{*}}$, Ph.D., Rosa H. Mulder ${ }^{1,2 *}$, MSc., Alexander Neumann ${ }^{1,2,3}$, Ph.D., Janine F. Felix ${ }^{2,4}$, Ph.D., Rianne Kok ${ }^{5}$, Ph.D., Marian J. BakermansKranenburg $^{6}$, Ph.D., Marinus H. van Ijzendoorn ${ }^{5,7}$, Ph.D., Henning Tiemeier ${ }^{1,8}$, Ph.D., Charlotte A.M. Cecil ${ }^{1,9,10}$, Ph.D.

Citation: Dall'Aglio L, Rijlaarsdam J, Mulder RH, Neumann A, Felix JF, Kok R, BakermansKranenburg MJ, van IJzendoorn MH, Tiemeier H \& Cecil CAM (2020). Epigenome-Wide Associations Between Observed Maternal Sensitivity and Offspring DNA Methylation: A Population-Based Prospective Study in Children. Psychological Medicine. 1-11. doi: 10.1017/S0033291720004353.

${ }^{1}$ Department of Child and Adolescent Psychiatry, Erasmus MC, University Medical Center RotterdamSophia Children's Hospital, Rotterdam, The Netherlands

${ }^{2}$ The Generation R Study Group, Erasmus MC, University Medical Center Rotterdam, Rotterdam, The Netherlands

${ }^{3}$ Lady Davis Institute for Medical Research, Jewish General Hospital, Montreal, QC, Canada

${ }^{4}$ Department of Pediatrics, Erasmus MC, University Medical Center Rotterdam, Rotterdam, The Netherlands

${ }^{5}$ Department of Psychology, Education and Child Studies, Erasmus University Rotterdam, Rotterdam, The Netherlands

${ }^{6}$ Clinical Child and Family Studies, Vrije Universiteit Amsterdam, Amsterdam, the Netherlands

${ }^{7}$ Primary Care Unit School of Clinical Medicine, University of Cambridge, UK

${ }^{8}$ Department of Social and Behavioral Sciences, Harvard T.H. Chan School of Public Health, Boston, USA

${ }^{9}$ Department of Psychology, Institute of Psychiatry, Psychology \& Neuroscience, King's College London, London, UK

${ }^{10}$ Department of Epidemiology, Erasmus MC, University Medical Center Rotterdam, Rotterdam, The Netherlands

*Authors contributed equally.

Corresponding author: Charlotte A.M. Cecil, Ph.D., at Wytemaweg 80, 3015 CN Rotterdam (office NA2917). Contact details: c.cecil@erasmusmc.nl; +31 107043390. 


\section{FINANCIAL SUPPORT}

The Generation R study is supported by Erasmus MC, Erasmus University Rotterdam, the Rotterdam Homecare Foundation, the Municipal Health Service Rotterdam area, the Stichting Trombosedienst \& Artsenlaboratorium Rijnmond, the Netherlands Organization for Health Research and Development (ZonMw), and the Ministry of Health, Welfare and Sport. DNAm data was funded by the Netherlands Genomics Initiative/Netherlands Organization for Scientific Research (NWO), Netherlands Consortium for Healthy Aging (project 050-060-810), the National Institute of Child and Human Development (R01HD068437), and by the Department of Internal Medicine (Genetic Laboratory) at Erasmus MC. This project received funding from the European Union's Horizon 2020 program (project 733206). Authors are supported by the Dutch Ministry of Education, Culture, and Science and the NWO (project 024.001.003 for Dr. Neumann, Prof. Tiemeier, Prof Bakermans-Kranenburg and Prof Van IJzendoorn), the Canadian Institutes of Health Research (Dr. Neumann), an NWO-VICI grant (NWO-ZonMW: 016.VICI.170.200 for Prof. Tiemeier, Ms. Dall'Aglio), an NWO VENI grant (project 91618147 for Dr. Rijlaarsdam), the European Joint Programming Initiative "A Healthy Diet for a Healthy Life" (project 529051022) (Dr. Felix) and the European Research Council grant (ERC AdG 669249, Prof. Bakermans-Kranenburg); and the Netherlands Organization for Scientific Research Spinoza Prize (Prof. Van IJzendoorn). 


\begin{abstract}
Background: Experimental work in animals has shown that DNA methylation (DNAm), an epigenetic mechanism regulating gene expression, is influenced by typical variation in maternal care. While emerging research in humans supports a similar association, studies to date have been limited to candidate gene and cross-sectional approaches, with a focus on extreme deviations in the caregiving environment.
\end{abstract}

Methods: Here, we investigated the prospective association between typical variation in maternal sensitivity and offspring epigenome-wide DNAm, in a population-based cohort of children $(N=235)$. Maternal sensitivity was observed when children were three- and four-yearsold. DNAm, quantified with the Infinium 450K array, was extracted at age six (whole blood). The influence of methylation quantitative trait loci (mQTLs), DNAm at birth (cord blood), and confounders (socioeconomic status, maternal psychopathology) was considered in follow-up analyses.

Results: Genome-wide significant associations between maternal sensitivity and offspring DNAm were observed at 13 regions $\left(p<1.06 \mathrm{e}^{-07}\right)$, but not at single sites. Follow-up analyses indicated that associations at these regions were in part related to genetic factors, confounders, and baseline DNAm levels at birth, as evidenced by the presence of mQTLs at five regions and estimate attenuations. Robust associations with maternal sensitivity were found at four regions, annotated to ZBTB22, TAPBP, ZBTB12, and DOCK4.

Conclusions: These findings provide novel leads into the relationship between typical variation in maternal caregiving and offspring DNA methylation in humans, highlighting robust regions of associations, previously implicated in psychological and developmental problems, immune functioning, and stress responses. 


\section{INTRODUCTION}

Parental sensitivity, i.e. the responsiveness to children's signals and communications, is an important predictor of developmental outcomes across the behavioral, emotional, and cognitive domains ${ }^{1-3}$. Low sensitivity of primary caregivers - typically mothers - has been associated with a host of negative outcomes, including higher risk for child psychopathology ${ }^{4,5}$, externalizing and internalizing problems ${ }^{1,6}$, and lower cognitive abilities ${ }^{7}$. This influence can be long-lasting, as shown by prospective human studies ${ }^{8,9}$ and experimental work in animals ${ }^{10}$. Yet, the molecular mechanisms underlying the enduring effects of maternal care on neurodevelopmental and behavioral outcomes in humans remain unclear.

Previous studies have provided initial support for DNA methylation (DNAm) - an epigenetic modification regulating gene expression - as a mechanism of interest for these processes ${ }^{11-13}$. DNAm involves the addition of a methyl group to DNA base pairs, primarily to the 5-carbon of cytosine nucleotides, resulting in 5-methylcytosine. DNAm is sensitive to both environmental and genetic influences ${ }^{13-15}$, with the latter being evidenced by changes in the methylome due to DNA variation, named methylation quantitative trait loci (mQTLs) ${ }^{16}$. Further, DNAm plays an essential role in healthy development and functioning by modulating the programming of wider biological systems (e.g. neural and immune functioning) and by coordinating key cellular processes (e.g. tissue differentiation) ${ }^{17}$. DNAm might thus represent a mechanism by which genetic and environmental factors, including the early caregiving environment, jointly and/or independently predict developmental outcomes ${ }^{14}$.

Most evidence of maternal care effects on DNAm comes from animal models. In a seminal study by Weaver et al. ${ }^{13}$, low levels of maternal care in the first week of life operationalized as the frequency of licking/grooming and arched-back nursing behaviors altered DNAm patterns in offspring at the glucocorticoid receptor ( $g r$, also known as $n r 3 c 1)$, a key regulator of stress response ${ }^{18}$. Importantly, these epigenetic changes were long-lasting, but could be reversed via cross-fostering or chemical interventions, leading to a normalization of physiological and behavioral responses to stress ${ }^{13,19}$. These findings generated widespread interest, as they indicated ( $i$ ) a causal role of maternal care on offspring's epigenetic dysregulation and downstream phenotypes, independent of genetic liability, and (ii) the possibility of influencing developmental trajectories through environmental interventions, mediated by DNAm. Since this initial work, other studies have replicated the effects of maternal care on $g r$ methylation in rodents ${ }^{20}$ and extended findings to demonstrate DNAm changes in other tissues and genes ${ }^{21-23}$ (e.g. brain derived neurotrophic factor $(b d n f)$ and oxytocin receptor (oxtr)) as well as in other species such as rhesus macaques ${ }^{24}$.

Although rodents and primates widely differ from humans in their caregiving, a number of similarities in maternal-infant relationships have been observed across mammalian species ${ }^{25,26}$. Parallels at the sensory, hormonal, behavioral, and brain circuit levels have been noted ${ }^{25-27}$, including the touch-based behavior characterizing rodents, primates, and humans in the early caregiving and the involvement of the limbic network in maternal-infant relationships (Feldman, 2016). Guided by the animal literature, a growing number of studies have sought to determine the extent to which different forms of caregiving and adversities affect DNAm in humans.

Human studies have focused on different forms of adversities ${ }^{28}$ including polyvictimization ${ }^{29}$, and on extreme deviations in the early caregiving environment, such as maltreatment ${ }^{30-34}$, institutionalization ${ }^{35}$, and maternal psychopathology ${ }^{36}$. Generally, literature 
focusing on the caregiving environment has provided preliminary support in line with animal findings, identifying, for example, similar increases in GR methylation in both postmortem hippocampal tissue and peripheral tissues from individuals exposed to childhood maltreatment or early-life stress ${ }^{20}$. Studies also indicate that epigenetic patterns associated with the caregiving environment extend beyond $G R$, implicating other genes related to, among other processes, neurodevelopment and stress, such as $O X T R$ and $B D N F$. Moreover, by leveraging epigenomewide DNAm, novel genes were identified (e.g. $K C N Q 2$, miR124-3) in relation to maltreatment and child abuse in individuals with post-traumatic stress disorder ${ }^{32}$, borderline personality disorder $^{33}$, and depression ${ }^{34}$.

While these results are promising and suggest a role of the caregiving environment in the human methylome, the current evidence in humans is limited in a number of key ways. First, since research has mostly focused on extreme deviations in the caregiving environment in selected samples, little is known about how typical variation in maternal sensitivity associates with offspring DNAm in the general population. Second, while studies on extreme deviations in maternal care have leveraged epigenome-wide approaches, literature on normative variation in maternal care has solely focused on candidate genes. This has impeded the identification of novel DNAm loci associated with maternal sensitivity, which might instead be detected with a hypothesis-free approach by performing an epigenome-wide association study (EWAS). Third, studies have typically relied on cross-sectional designs, in which the early caregiving environment is measured retrospectively via the use of questionnaires, raising doubts about the directionality of observed associations and about the validity of measurements, which may be prone to recall bias ${ }^{37,38}$. Moreover, previous studies rarely investigated whether the identified associations may be confounded by genetic background shared between parents and offspring. The examination of the relationship between maternal care and DNAm might indeed capture intergenerational genetic transmission. Lastly, the influence on offspring DNAm of factors preceding postnatal maternal care, including the prenatal environment, remains unexplored.

To address these gaps, we firstly examined how typical variation in observed maternal sensitivity prospectively associates with epigenome-wide DNAm patterns in a general population of children. Secondly, with a series of follow-up analyses, we explored the extent to which associations reflected genetic influences as well as confounding by "baseline" DNAm levels at birth, which precede exposure to postnatal maternal care and might constitute a biological indicator of the prenatal environment as well as of genetic effects on the methylome.

\section{MATERIALS AND METHODS Participants}

The present research was embedded in the Generation R Study, a prospective populationbased cohort study from fetal life onwards in Rotterdam, The Netherlands ${ }^{39}$ (Supplementary Information 1). Ethical approval was obtained from the Medical Ethics Committee of Erasmus MC, University Medical Center Rotterdam. For the purposes of this study, children within the Generation R Study with data on maternal sensitivity (at three and/or four years) and DNAm (at six years) were selected $(N=235)$. Since 5 sibling-pairs were present, we later excluded one sibling per pair $(N=230)$ to ensure genetic relatedness did not impact results. 
Participant characteristics are shown in Supplementary Table 1. Participants with data on both maternal sensitivity and DNAm (age six) differed from participants invited to the age six assessment in gestational age at birth $\left(M_{\text {subsample }}=40.3\right.$ weeks $(\mathrm{SD}=1.4), M_{\text {fullsample }}=39.8(\mathrm{SD}=$ $\left.1.9), t=5.6, p=6.50 \mathrm{e}^{-08}\right)$, but not other covariates.

\section{Measures}

\section{Maternal sensitivity}

Maternal sensitivity was assessed at ages three and four years through observations of mother-child interactions during teaching tasks too complex for the age of the child. These involved $(i)$ building a tower and (ii) completing an etch-a-sketch drawing. Mother-child interactions were recorded and subsequently coded, according to the revised Erickson 7-point rating scales ${ }^{40}$, based on two interdependent subscales: intrusiveness (IN) and supportive presence (SP), which together form the maternal sensitivity construct. Inter-coder reliability amounted to 0.81 at age three and 0.84 at age four ${ }^{41}$.

Eight measures of maternal sensitivity (i.e. IN and SP scales x two tasks $\mathrm{x}$ two timepoints) were available. IN scores were reversed, and both IN and SP scores were standardized. An overall maternal sensitivity score was calculated, for participants with data at age three and/or four, by averaging such standardized measures ${ }^{42}$. This was done in line with previous literature ${ }^{41}$, due to the stability of the maternal sensitivity scores between age three and four years ${ }^{1}$, the temporality of these assessments, which both precede DNAm at age six, and to maximize our sample size. Cronbach's alpha reliability of the obtained measure was acceptable (Cronbach's $\alpha=0.70)^{43}$.

\section{DNA methylation}

DNAm in whole blood at age six was used for our epigenome-wide analyses. This was selected due to it being the closest DNAm assessment after maternal sensitivity observations (age three and four years), and to test the prospective association of maternal sensitivity with DNAm. Based on previous studies in animals, which found maternal care to have long-lasting influences on the methylome ${ }^{13}$, we expected for maternal care effects to endure in early childhood.

To obtain DNAm data, DNA extraction and bisulfite conversion via the EZ-96 DNA Methylation kit (Shallow) (Zymo Research Corporation, Irvine, USA) were performed, and samples were processed with the Illumina Infinium HumanMethylation450 BeadChip (Infinium 450K), which measures $485577 \mathrm{CpGs}$. The incorporating control probe adjustment and reduction of global correlation pipeline ${ }^{44}$ was employed for the preparation and normalization of the data using R. Firstly, the minfi package ${ }^{45}$ in $\mathrm{R}$ was used to read the idat files. Probes that had a detection p-value above background (based on the sum of methylated and unmethylated intensity values) $\geq 1 \mathrm{e}^{-16}$ were set to missing per array. Next, the intensity values were stratified by autosomal and non-autosomal probes and quantile normalized for each of the six probe-type categories separately: type II red/green, type I methylated red/green and type I unmethylated $\mathrm{red} / \mathrm{green}$. For each probe, DNAm levels were indexed by beta values (i.e. the ratio of methylated signal divided by the sum of the methylated and unmethylated signal $[\mathrm{M} /(\mathrm{M}+\mathrm{U}+$ 100)]). Quality control procedures were additionally performed (e.g. check for sex mismatch). Only arrays with a call rate above $95 \%$ per sample were considered for additional processing. 
DNAm data was winsorized (> $3 \mathrm{SD}$ ) to reduce the influence of potential outliers. In total, we obtained information on 457872 autosomal sites in 493 six-year-olds.

We additionally used DNAm data collected at birth in cord blood for a follow-up analysis. This was subject to the same pipeline as the DNAm data at age six and was also measured based on the Infinium $450 \mathrm{~K}$ BeadChip. Only CpGs identified as significant or within DNAm significant regions were selected for these analyses.

\section{Covariates}

All analyses were adjusted for a key set of potential covariates guided by previous literature ${ }^{46-49}$, including batch effects (plate number), sex, gestational age at birth, maternal smoking during pregnancy (never smoked, smoked until pregnancy known, continued during pregnancy), and estimated cell-type proportions ${ }^{50}$ (Supplementary Information 1). We additionally adjusted for two sets of covariates: (i) maternal education (highest level completed) as proxy for socioeconomic status, and postnatal maternal psychopathology (Brief Symptom Inventory), and (iii) DNAm levels at birth (cord blood tissue), together with respective cell-type and batch effect adjustments (Supplementary Information 1).

\section{Statistical Analyses}

Analyses were performed in $\mathrm{R}$ (version 4.0.0) and are described in-depth in Supplementary Information 1. A probe-level EWAS (multiple linear regression models) was run with the CpGassoc R package ${ }^{51}$, to test for associations of maternal sensitivity with each DNAm site individually (Bonferroni epigenome-wide significance threshold: $p<1.09 \mathrm{e}^{-07}$ ). To account for potential bias and inflation, the $B A C O N \mathrm{R}$ package ${ }^{52}$ was used.

Moreover, to capture correlations across CpGs, reduce data dimensionality, and attenuate the multiple testing burden, a regional-level EWAS was performed by using the R package DMRff $^{53}$. This estimates correlations across nominally-significant probes within a $500 \mathrm{bp}$ window (default setting) and combines the EWAS summary statistics of such neighboring CpGs to identify differentially methylated regions while accounting for multiple testing with a Bonferroni procedure in both gene regions and sub-regions ${ }^{54}$.

A candidate gene look-up was also performed to maximize comparability with previously reported DNAm-maternal care associations. To date, DNAm levels of four genes have been associated with maternal care in humans ${ }^{55-58}$, by at least one study: $G R, B D N F$, the serotonin receptor (SLC6A4), and OXTR. We looked-up the EWAS results for probes located within these genes, as annotated in the HumanMethylation450 v1.2 Manifest File. Following previous studies 29,59 , gene-level Bonferroni correction was used as significance threshold (i.e. $p<.05 /$ number of annotated probes).

To identify enriched biological pathways, we performed an in-house gene ontology $(G O)$ analysis ${ }^{59-61}$ on sites with $\mathrm{p}<.001$ in the probe-level EWAS, in line with previous literature $59,60,62,63$. We performed p-value adjustments based on default procedures ${ }^{61}$. Enriched pathways were confirmed by an independent GO approach from the missMethyl R package ${ }^{64}(p<.05)$.

Finally, a series of follow-up analyses were run. Firstly, the influence of genetic factors on our top hits (i.e. Bonferroni-significant sites or sites within Bonferroni-significant DNAm regions) was assessed by drawing on an $m Q T L$ database ${ }^{16}$ (www.mqtldb.org). We examined whether hits were associated with known mQTLs during childhood, based on the results from a 
genome-wide complex trait conditional analysis. Secondly, we explored the robustness of top hits to additional adjustments for $(i)$ postnatal maternal education and maternal psychopathology $(N=223)$ and (ii) pre-exposure DNAm $(N=226)$. The latter was done to account for the effect of DNAm at birth on DNAm at age six and to capture potential pre-existing influences (e.g. intrauterine exposures) on DNAm in childhood. Spearman correlations between DNAm at birth and age six were also calculated, per CpG. Thirdly, based on a list of our $\mathrm{CpG}$ hits, the in-house gene ontology analysis and missMethyl validation were run, with the same procedures as the main GO analysis specified above. Finally, to understand the relevance of our findings to the brain, which is linked to the caregiving environment ${ }^{13,41}$, we looked up brain-blood concordance values for our top hits using the BECon online tool (https://redgar598.shinyapps.io/BECon/) ${ }^{65}$.

\section{RESULTS}

\section{Probe-level EWAS}

Maternal sensitivity was not associated with any single $\mathrm{CpG}$ at age six, after genomewide correction $\left(p<1.09 \mathrm{e}^{-07}\right)$ (Figure 1 , Supplementary Table 2 ). BACON analysis revealed a normal lambda $(\lambda=1.00)$, minimal bias (Bayesian estimate of bias $=-0.002)$ and deflation in the test results - indicative of low power (Bayesian inflation factor $=0.925)$ (Supplementary Figure 1). Following BACON correction for deflation, one intergenic $\mathrm{CpG}$ reached genome-wide significance: $\operatorname{cg} 25628898$ (estimate $=-0.008 ; \mathrm{SE}=0.002 ; p=1.03 \mathrm{e}^{-07}$ ) (Supplementary Table 2).

\section{Regional-level EWAS}

With a regional-level EWAS, we identified 13 DNAm regions associated with maternal sensitivity $\left(p<1.09 \mathrm{e}^{-07} ; \alpha=0.05\right.$ ) (Table 1, Figure 2, Supplementary Table 3), spanning 143 CpGs. The top three DNAm regions coincided with the ANKMY1, RNF39, and ZBTB22 and $T A P B P$ genes (Table 1). The largest estimates were shown at regions encompassing COLEC11 and DOCK4. None of the CpGs within our significant regions was related to prenatal maternal smoking, based on previous research in neonates and children (Joubert et al., 2016 Rzehak et al., 2016), suggesting adjustments in the EWAS accounted for its confounding role. When siblings $(N=230)$ were excluded all but one region (annotated to $R N F 5 P 1, R N F 5, A G P A T 1)$ remained significantly associated with maternal sensitivity.

\section{Candidate gene look-up}

The candidate gene look-up showed that, of the four selected genes (NR3C1, BDNF, SLC6A4, OXTR), which included 14 to 74 sites, no CpG met Bonferroni-adjusted gene-wide significance in association with maternal sensitivity (Table 2, Supplementary Table 4). Only three sites reached nominal significance $(p<.05)$.

\section{Gene ontology}

The in-house GO analysis, based on sites with $p<0.001$ in the probe-level EWAS, revealed enrichment for 148 pathways. Yet, this threshold might have been overinclusive. Thirty-nine of the 148 pathways were confirmed by the missMethyl GO method $(p<0.05)$ (Supplementary Table 5). Both methods indicated enrichment for, among others, calcium ion channels functioning, phosphorylation, and tissue and cell polarity. 


\section{Follow-up analyses}

Firstly, an mQTL search revealed that five of the 13 significant DNAm regions contained at least one CpG associated with one or more known SNPs (Table 3, Supplementary Table 6). Eight regions, including ZBTB22/TAPBP (one of our top regions), did not present any mQTLs. Of the 143 sites within the 13 significant regions, 22\% $(n=31)$ associated with one or more known SNPs. All associations were in cis.

Secondly, after additional adjustments for socioeconomic status and maternal psychopathology, associations attenuated at seven regions (median $=-1 \%$, range $=-44 \%-13 \%$ ). Regions which did not decrease in effect were TAPBP, RNF39, two non-annotated regions, $A N K M Y 1$, and $A L O X 12 P 2$ (Supplementary Table 7). When adjusting for pre-exposure DNAm levels, (Supplementary Table 8 ), associations attenuated at ten regions (median $=-45 \%$, range $=$ $-97 \%-17 \%$ ), with RNF39 being the most affected. Regions whose estimates did not decrease were $Z B T B 12$, FBXO44/FBXO2, and a non-annotated region (chromosome 7). The median correlation between each CpG DNAm levels at birth and age six was of Rho $=0.43$ (range: 0.11 - 0.86) (Supplementary Table 9).

Thirdly, in a follow-up GO analysis, based on the sites within the significant DNAm regions $(n=143)$, enrichment was found at 63 pathways (in-house method). Of these, 33 were validated by missMethyl $(p<0.05)$. Both methods indicated enrichment for, among others, several lipoprotein processes (e.g. particle remodeling), and peptide binding (Supplementary Table 10).

Lastly, of the 13 significant DNAm regions, six contained half or more sites with greater than average blood-brain tissue concordance ${ }^{65}$ in at least one brain tissue (for BA7 $r>|.36|$, for BA10 $r>|.40|$, for BA20 $r>|.33|$ ), for a total of 67 sites (Supplementary Table 11) (not empirically tested).

\section{DISCUSSION}

This is the first epigenome-wide study investigating the prospective association between typical variation in maternal sensitivity (observed) and offspring DNAm, in a general population of children. Genome-wide significant associations were observed at 13 DNAm regions, four of which did not contain mQTLs and were minimally affected by adjustments for postnatal confounders and by pre-exposure DNAm levels, thus showing robustness in associations.

\section{Summary of Key Findings}

Our first aim was to examine the prospective relationship between maternal sensitivity and child DNAm using complementary approaches. Firstly, no individual $\mathrm{CpG}$ was identified in the probe-level EWAS after genome-wide correction. This might indicate that associations at a site-level are subtle and challenging to identify, especially considering this study assessed typical variation in maternal care as opposed to extreme deviations (e.g. abuse). The high multiple testing correction burden that probe-level EWASs entail may also impede the detection of single sites of small effect, which could be uncovered with larger samples. For instance, with our sample $(N=235)$ and model (multiple linear regression, 10 predictors), $80 \%$ power, and a genome-wide threshold, only moderate estimates (as small as 0.27 ) could be detected.

When employing a regional approach, which can detect weaker but more widespread signals by accounting for correlations across CpGs, 13 DNAm regions were significantly 
associated with maternal sensitivity $\left(p<1.06 \mathrm{e}^{-07}, \alpha=.05\right)$. These findings support the presence of offspring methylomic signatures of maternal care, which may be best uncovered through hypothesis-free approaches with methods capturing the correlational patterns of DNAm. Yet, replication of these findings is needed, and the possibility of false-positive findings should not be excluded. Notably, when considering a more stringent significance threshold $\left(p<2.18 \mathrm{e}^{-09} ; \alpha=\right.$ $.001)$, as suggested to reduce false-positive rates ${ }^{68}$, most of the regions $(77 \%, N=10)$ remained significantly related to maternal sensitivity.

Further, we failed to detect an association between maternal sensitivity and DNAm variation at candidate genes previously identified by studies of maternal care in humans ${ }^{55-58}$. Inconsistencies may reflect several factors, including differences in sample characteristics (e.g. psychiatric vs. population-based samples), maternal care assessments (retrospective vs. prospective reports) and analysis (e.g. gene regions covered by pyrosequencing vs. Infinium $450 \mathrm{~K})$. Lastly, candidate gene studies may be particularly vulnerable to false positives, as shown in the genetic field ${ }^{69}$.

As a second aim, we explored whether identified maternal sensitivity-DNAm associations may be influenced by genetic factors, based on mQTL mapping. Twenty-two percent of the sites in our significant regions were linked to known SNPs. This suggests that associations for those sites may be in part confounded by genetic factors and corroborates previous research highlighting DNAm responsiveness to both external exposures and genetic variation ${ }^{14}$. However, the presence of mQTLs alone does not preclude environmental effects. Indeed, recent studies have found that interindividual variability in DNAm is primarily explained by gene-environment combinations (additive and interactive effects) ${ }^{70,71}$. Moreover, mQTLs were identified based on a publicly available database, as our sample was underpowered to directly test for genetic confounding. Future studies employing genetically-sensitive designs could more precisely quantify the effect of maternal sensitivity on DNAm by directly modeling genetic influences.

When exploring the robustness of findings to additional adjustments, we observed attenuations at half of the regions, after controlling for socioeconomic status and maternal psychopathology. When considering pre-exposure DNAm levels, estimates attenuated at most regions. Although neonatal methylomic patterns were measured in cord blood at birth and not in peripheral blood (used at age six), which may lead to additional differences, these findings indicate that associations partly reflected pre-existing DNAm levels. This was clearly exemplified by $R N F 39$, a region strongly associated with sensitivity, robust to postnatal confounders, and genetic influences. After adjustments, its estimate reduced by $97 \%$, showing that associations did not result from postnatal caregiving, as they were already present at baseline (birth). These findings cast doubts on previous studies of caregiving which did not consider preexposure DNAm levels, and raise questions on the directionality of associations between maternal care and DNAm, as well as on the potential role of other confounders affecting child DNAm at birth and in childhood, and maternal sensitivity (e.g. shared genetics, maternal distress).

Here, we highlight four "high-confidence" associations with maternal caregiving, which were not linked to any mQTLs, and were most robust to adjustments for confounders and preexposure DNAm levels. These spanned (i) ZBTB22/TAPBP, (ii) ZBTB12, (iii) DOCK4, and (iv) a non-annotated region in chromosome four. All four genes are protein-coding ${ }^{18}$. DOCK4 is 
implicated in neuronal processes, such as neuronal migration, and dendritic arborization ${ }^{72}$ and its DNAm region presented higher than average blood-BA10 concordance in this study. ZBTB22 and $Z B T B 12$ are involved in transcriptional regulation and nuclear chromatin localization ${ }^{73}$. These two genes, together with TAPBP, are within the Major Histocompatibility Complex (MHC). While these associations should be carefully interpreted as the MHC is characterized by extensive linkage disequilibrium ${ }^{74}$, this genomic region plays an important role in immune functioning and has been implicated in neuronal plasticity ${ }^{75,76}$. TAPBP specifically is involved in MHC class I protein complex assembly, gene expression regulation, and immunodeficiency ${ }^{73}$. In this study, enrichment for MHC class I protein assembly and peptide binding was found for maternal sensitivity, suggesting that such exposure might enact on $T A P B P$-related functions via DNAm.

Generally, our high-confidence genes have been previously associated with psychological and developmental problems, inflammation, and stress-responses. Molecular changes were shown at TAPBP for major depressive disorder and suicide ${ }^{77}, T A P B P$ and DOCK 4 for schizophrenia ${ }^{78-80}, Z B T B 22$ for intellectual disability ${ }^{73}$ and psychopathologies following hypercortisolism ${ }^{81}$, and $D O C K 4$ for autism and dyslexia ${ }^{82,83}$. Enrichment for pathways including Dock4 has been repeatedly associated with stress-related responses in mice ${ }^{84-86}$, while ZBTB12 DNAm is related to markers of inflammation (e.g. white blood cell counts) ${ }^{87}$.

\section{Limitations and Suggestions for Future Research:}

Our findings should be interpreted in light of several limitations. Firstly, identified associations may have been influenced by additional parental factors that we could not control for in the present study, either because this information was not available (e.g. parental temperament, parental genotype) or due to the low number of cases (e.g. maternal medication and substance use in pregnancy). Nevertheless, we did control for the most important maternal confounders (smoking during pregnancy, socioeconomic status, psychopathology). Secondly, if unmeasured changes in maternal sensitivity and covariates occurred during the two-to-three-year time-lag between our exposure and outcome, noise would be introduced in the identified associations. A prospective design, as opposed to a cross-sectional one, remains however preferable due to the possibility to better understand the directionality of associations. Nonetheless, repeated postnatal measurements of both DNAm and maternal sensitivity would be ideal to longitudinally examine how associations change over time and disentangle directionality. Thirdly, we did not have information on whether the mothers included in this study were primary or secondary caregivers (at four years only). Yet, within Generation R, most mothers are primary caregivers ${ }^{88}$. Additionally, while the use of the Infinium $450 \mathrm{~K}$ provided novel insights into the genes affected by maternal sensitivity, future research should employ, when possible, the EPIC $850 \mathrm{~K}$ array due to its wider and more diverse genomic coverage ${ }^{89}$. Lastly, our investigation solely focused on the association of maternal sensitivity on the child methylome. Related molecular signatures, such as transcription changes and epigenetic clocks, could be examined in future research to better understand the biological consequences of maternal care.

In conclusion, this population-based study supports a prospective association of typical variation in maternal sensitivity with epigenome-wide DNAm in children. We highlight four DNAm regions that showed the strongest associations with maternal sensitivity as well as minimal evidence of genetic and pre-exposure influences, and which should thus be prioritized in future research. These results permit further delineation of the relationship between DNA 
methylation and maternal care in humans and warrant confirmation by future research with large, longitudinal, and genetically-sensitive studies.

\section{ACKNOWLEDGMENTS}

We thank children and parents, midwives, general practitioners, hospitals, and pharmacies in Rotterdam for their contribution to Generation R, the Genetic Laboratory of the Department of Internal Medicine at Erasmus MC for the generation and management of the Infinium 450K, Mr. Verbiest, Ms. Higgins, Ms. Jhamai, Dr. Stolk, and Mr. Verkerk for their aid in the EWAS database creation, Dr. Teumer for the contribution to quality control and normalization, and Dr. Suderman for answering all our queries on the $d m r f f$ method.

\section{CONFLICT OF INTEREST}

None.

\section{ETHICAL STANDARDS}

The authors assert that all procedures contributing to this work comply with the ethical standards of the relevant national and institutional committees on human experimentation and with the Helsinki Declaration of 1975, as revised in 2008. 
Maternal sensitivity and offspring DNA methylation

\section{REFERENCES}

1. Kok R, Linting M, Bakermans-Kranenburg MJ, et al. Maternal Sensitivity and Internalizing Problems: Evidence from Two Longitudinal Studies in Early Childhood. Child Psychiatry Hum Dev. 2013;44(6):751-765. doi:10.1007/s10578-013-0369-7

2. Madigan S, Prime H, Graham SA, et al. Parenting Behavior and Child Language: A Meta-analysis. Pediatrics. 2019;144(4). doi:10.1542/peds.2018-3556

3. Thomas JC, Letourneau N, Campbell TS, Tomfohr-Madsen L, Giesbrecht GF. Developmental origins of infant emotion regulation: Mediation by temperamental negativity and moderation by maternal sensitivity. Dev Psychol. 2017;53(4):611-628. doi:10.1037/dev0000279

4. Kimbrel NA, Nelson-Gray RO, Mitchell JT. Reinforcement sensitivity and maternal style as predictors of psychopathology. Personal Individ Differ. 2007;42(6):1139-1149. doi:10.1016/j.paid.2006.06.028

5. Haltigan JD, Roisman GI, Fraley RC. The predictive significance of early caregiving experiences for symptoms of psychopathology through midadolescence: Enduring or transient effects? Dev Psychopathol. 2013;25(1):209-221. doi:10.1017/S0954579412000260

6. Rijlaarsdam J, Stevens GWJM, Jansen PW, et al. Maternal Childhood Maltreatment and Offspring Emotional and Behavioral Problems: Maternal and Paternal Mechanisms of Risk Transmission. Child Maltreat. 2014;19(2):67-78. doi:10.1177/1077559514527639

7. Bernier A, Carlson SM, Deschênes M, Matte-Gagné C. Social factors in the development of early executive functioning: a closer look at the caregiving environment. Dev Sci. 2012;15(1):12-24. doi:10.1111/j.1467-7687.2011.01093.x

8. Raby KL, Roisman GI, Fraley RC, Simpson JA. The Enduring Predictive Significance of Early Maternal Sensitivity: Social and Academic Competence Through Age 32 Years. Child Dev. 2015;86(3):695-708. doi:10.1111/cdev.12325

9. Stams G-JJM, Juffer F, van IJzendoorn MH. Maternal sensitivity, infant attachment, and temperament in early childhood predict adjustment in middle childhood: The case of adopted children and their biologically unrelated parents. Dev Psychol. 2002;38(5):806-821. doi:10.1037//0012-1649.38.5.806

10. Meaney MJ. Maternal Care, Gene Expression, and the Transmission of Individual Differences in Stress Reactivity Across Generations. Annu Rev Neurosci. 2001;24(1):1161-1192. doi:10.1146/annurev.neuro.24.1.1161

11. Mulder RH, Rijlaarsdam J, Van IJzendoorn MH. DNA Methylation: A Mediator Between Parenting Stress and Adverse Child Development? In: Deater-Deckard K, Panneton R, eds. Parental Stress and Early Child Development: Adaptive and Maladaptive Outcomes. Springer International Publishing; 2017:157-180. doi:10.1007/978-3-319-55376-4_7

12. Szyf M. The Genome- and System-Wide Response of DNA Methylation to Early Life Adversity and its Implication on Mental Health. Can J Psychiatry. 2013;58(12):697-704. doi:10.1177/070674371305801208 
Maternal sensitivity and offspring DNA methylation

13. Weaver ICG, Cervoni N, Champagne FA, et al. Epigenetic programming by maternal behavior. Nat Neurosci. 2004;7(8):847-854. doi:10.1038/nn1276

14. Ladd-Acosta C, Fallin MD. The role of epigenetics in genetic and environmental epidemiology. Epigenomics. 2016;8(2):271-283. doi:https://doi.org/10.2217/epi.15.102

15. Smith AK, Kilaru V, Kocak M, et al. Methylation quantitative trait loci (meQTLs) are consistently detected across ancestry, developmental stage, and tissue type. BMC Genomics. 2014;15(1):145. doi:10.1186/1471-2164-15-145

16. Gaunt TR, Shihab HA, Hemani G, et al. Systematic identification of genetic influences on methylation across the human life course. Genome Biol. 2016;17:61. doi:10.1186/s13059-016-0926z 10.1186/s13059-016-0926-z [pii]

17. Carey N. Life as we know it now. In: The Epigenetics Revolution. Columbia University Press; 2012:72-73.

18. Geer LY, Marchler-Bauer A, Geer RC, et al. The NCBI BioSystems database. Nucleid Acids Res. 2010;38:D492-6. doi:https://doi.org/10.1093/nar/gkp858

19. Weaver ICG, Champagne FA, Brown SE, et al. Reversal of Maternal Programming of Stress Responses in Adult Offspring through Methyl Supplementation: Altering Epigenetic Marking Later in Life. J Neurosci. 2005;25(47):11045-11054. doi:10.1523/JNEUROSCI.3652-05.2005

20. Turecki G, Meaney MJ. Effects of the Social Environment and Stress on Glucocorticoid Receptor Gene Methylation: A Systematic Review. Biol Psychiatry. 2016;79(2):87-96. doi:10.1016/j.biopsych.2014.11.022

21. Doherty TS, Forster A, Roth TL. Global and gene-specific DNA methylation alterations in the adolescent amygdala and hippocampus in an animal model of caregiver maltreatment. Behav Brain Res. 2016;298(0 0):55-61. doi:10.1016/j.bbr.2015.05.028

22. Beery AK, McEwen LM, MacIsaac JL, Francis DD, Kobor MS. Natural variation in maternal care and cross-tissue patterns of oxytocin receptor gene methylation in rats. Horm Behav. 2016;77:42-52. doi:10.1016/j.yhbeh.2015.05.022

23. Blaze J, Asok A, Borrelli K, et al. Intrauterine exposure to maternal stress alters Bdnf IV DNA methylation and telomere length in the brain of adult rat offspring. Int J Dev Neurosci. 2017;62:5662. doi:10.1016/j.ijdevneu.2017.03.007

24. Provençal N, Suderman MJ, Guillemin C, et al. The signature of maternal rearing in the methylome in rhesus macaque prefrontal cortex and t cells. J Neurosci Off J Soc Neurosci. 2012;32(44):1562615642. doi:10.1523/JNEUROSCI.1470-12.2012

25. Feldman R. The neurobiology of mammalian parenting and the biosocial context of human caregiving. Horm Behav. 2016;77:3-17. doi:10.1016/j.yhbeh.2015.10.001

26. Knop J, Joëls M, van der Veen R. The added value of rodent models in studying parental influence on offspring development: opportunities, limitations and future perspectives. Curr Opin Psychol. 2017;15:174-181. doi:10.1016/j.copsyc.2017.02.030 
27. Glynn LM, Baram TZ. The influence of unpredictable, fragmented parental signals on the developing brain. Front Neuroendocrinol. 2019;53:100736. doi:10.1016/j.yfrne.2019.01.002

28. Daskalakis NP, Yehuda R. Site-specific methylation changes in the glucocorticoid receptor exon 1F promoter in relation to life adversity: systematic review of contributing factors. Front Neurosci. 2014;8. doi:10.3389/fnins.2014.00369

29. Marzi SJ, Sugden K, Arseneault L, et al. Analysis of DNA Methylation in Young People: Limited Evidence for an Association Between Victimization Stress and Epigenetic Variation in Blood. Am J Psychiatry. 2018;175(6):517-529. doi:10.1176/appi.ajp.2017.17060693

30. Cecil CAM, Smith RG, Walton E, Mill J, McCrory EJ, Viding E. Epigenetic signatures of childhood abuse and neglect: Implications for psychiatric vulnerability. J Psychiatr Res. 2016;83:184-194. doi:10.1016/j.jpsychires.2016.09.010

31. Gouin JP, Zhou QQ, Booij L, et al. Associations among oxytocin receptor gene ( OXTR ) DNA methylation in adulthood, exposure to early life adversity, and childhood trajectories of anxiousness. Sci Rep. 2017;7(1):7446. doi:10.1038/s41598-017-07950-х

32. Mehta D, Klengel T, Conneely KN, et al. Childhood maltreatment is associated with distinct genomic and epigenetic profiles in posttraumatic stress disorder. Proc Natl Acad Sci. 2013;110(20):8302-8307. doi:10.1073/pnas.1217750110

33. Stenz L, Prados J, Courtet P, et al. Borderline personality disorder and childhood maltreatment: A genome-wide methylation analysis. Eur Psychiatry. 2016;33(S1):S183-S183. doi:10.1016/j.eurpsy.2016.01.400

34. Weder N, Zhang H, Jensen K, et al. Child Abuse, Depression, and Methylation in Genes Involved With Stress, Neural Plasticity, and Brain Circuitry. J Am Acad Child Adolesc Psychiatry. 2014;53(4):417-424.e5. doi:10.1016/j.jaac.2013.12.025

35. Naumova OYu, Lee M, Koposov R, Szyf M, Dozier M, Grigorenko EL. Differential patterns of whole-genome DNA methylation in institutionalized children and children raised by their biological parents. Dev Psychopathol. 2012;24(01):143-155. doi:10.1017/S0954579411000605

36. Oberlander TF, Weinberg J, Papsdorf M, Grunau R, Misri S, Devlin AM. Prenatal exposure to maternal depression, neonatal methylation of human glucocorticoid receptor gene (NR3C1) and infant cortisol stress responses. Epigenetics. 2008;3(2):97-106. doi:10.4161/epi.3.2.6034

37. Reuben A, Moffitt TE, Caspi A, et al. Lest we forget: comparing retrospective and prospective assessments of adverse childhood experiences in the prediction of adult health. J Child Psychol Psychiatry. 2016;57(10):1103-1112. doi:10.1111/jcpp.12621

38. Baldwin JR, Reuben A, Newbury JB, Danese A. Agreement Between Prospective and Retrospective Measures of Childhood Maltreatment: A Systematic Review and Meta-analysis. JAMA Psychiatry. 2019;76(6):584-593. doi:10.1001/jamapsychiatry.2019.0097

39. Kooijman MN, Kruithof CJ, van Duijn CM, et al. The Generation R Study: design and cohort update 2017. Eur J Epidemiol. 2016;31(12):1243-1264. doi:10.1007/s10654-016-0224-9 
Maternal sensitivity and offspring DNA methylation

40. Egeland B, Erickson MF, Clemenhagen-Moon J, Hiester MK, Korfmacher J. 24 months tools coding manual. Project STEEP-revised 1990 from Mother-Child project scales. Published online 1990.

41. Kok R, Thijssen S, Bakermans-Kranenburg MJ, et al. Normal Variation in Early Parental Sensitivity Predicts Child Structural Brain Development. J Am Acad Child Adolesc Psychiatry. 2015;54(10):824-831.e1. doi:10.1016/j.jaac.2015.07.009

42. Cents RAM, Kok R, Tiemeier H, et al. Variations in maternal 5-HTTLPR affect observed sensitive parenting. J Child Psychol Psychiatry. 2014;55(9):1025-1032. doi:10.1111/jcpp.12205

43. Cortina JM. What is coefficient alpha? An examination of theory and applications. J Appl Psychol. 1993;78(1):98-104. doi:10.1037/0021-9010.78.1.98

44. Lehne B, Drong AW, Loh M, et al. A coherent approach for analysis of the Illumina HumanMethylation450 BeadChip improves data quality and performance in epigenome-wide association studies. Genome Biol. 2015;16(1):37. doi:10.1186/s13059-015-0600-x

45. Aryee MJ, Jaffe AE, Corrada-Bravo H, et al. Minfi: a flexible and comprehensive Bioconductor package for the analysis of Infinium DNA methylation microarrays. Bioinformatics. 2014;30(10):1363-1369. doi:10.1093/bioinformatics/btu049

46. Birney E, Smith GD, Greally JM. Epigenome-wide Association Studies and the Interpretation of Disease -Omics. PLoS Genet. 2016;12:e1006105. doi:10.1371/journal.pgen.1006105 PGENETICSD-16-00215 [pii]

47. Breton CV, Byun H-M, Wenten M, Pan F, Yang A, Gilliland FD. Prenatal Tobacco Smoke Exposure Affects Global and Gene-specific DNA Methylation. Am J Respir Crit Care Med. 2009;180(5):462-467. doi:10.1164/rccm.200901-0135OC

48. Rakyan VK, Down TA, Balding DJ, Beck S. Epigenome-wide association studies for common human diseases. Nat Rev Genet. 2011;12(8):529-541. doi:https://doi.org/10.1038/nrg3000

49. Liang L, Cookson WOC. Grasping nettles: cellular heterogeneity and other confounders in epigenome-wide association studies. Hum Mol Genet. 2014;23(R1):R83-R88. doi: $10.1093 / \mathrm{hmg} / \mathrm{ddu} 284$

50. Houseman EA, Accomando WP, Koestler DC, et al. DNA methylation arrays as surrogate measures of cell mixture distribution. BMC Bioinformatics. 2012;13(1):86. doi:10.1186/1471-2105-13-86

51. Barfield RT, Kilaru V, Smith AK, Conneely KN. CpGassoc: an R function for analysis of DNA methylation microarray data. Bioinformatics. 2012;28(9):1280-1281.

doi:10.1093/bioinformatics/bts124

52. van Iterson M, van Zwet EW, Bios Consortium, Heijmans BT. Controlling bias and inflation in epigenome- and transcriptome-wide association studies using the empirical null distribution. Genome Biol. 2017;18:19. doi:10.1186/s13059-016-1131-9 10.1186/s13059-016-1131-9 [pii]

53. Suderman M, Staley JR, French R, Arathimos R, Simpkin A, Tilling K. dmrff: identifying differentially methylated regions efficiently with power and control. bioRxiv. Published online December 31, 2018:508556. doi:10.1101/508556 
Maternal sensitivity and offspring DNA methylation

54. Suderman M, Staley JR, French R, Arathimos R, Simpkin A, Tilling K. Dmrff: Identifying Differentially Methylated Regions Efficiently with Power and Control. Bioinformatics; 2018. doi:10.1101/508556

55. Conradt E, Hawes K, Guerin D, et al. The Contributions of Maternal Sensitivity and Maternal Depressive Symptoms to Epigenetic Processes and Neuroendocrine Functioning. Child Dev. 2016;87(1):73-85. doi:10.1111/cdev.12483

56. Unternaehrer E, Meyer AH, Burkhardt SCA, et al. Childhood maternal care is associated with DNA methylation of the genes for brain-derived neurotrophic factor ( $B D N F$ ) and oxytocin receptor ( OXTR ) in peripheral blood cells in adult men and women. Stress. 2015;18(4):451-461. doi:10.3109/10253890.2015.1038992

57. Provenzi L, Fumagalli M, Giorda R, et al. Maternal Sensitivity Buffers the Association between SLC6A4 Methylation and Socio-Emotional Stress Response in 3-Month-Old Full Term, but not very Preterm Infants. Front Psychiatry. 2017;8. doi:10.3389/fpsyt.2017.00171

58. Bosmans G, Young JF, Hankin BL. NR3C1 methylation as a moderator of the effects of maternal support and stress on insecure attachment development. Dev Psychol. 2018;54(1):29-38. doi: $10.1037 / \operatorname{dev} 0000422$

59. Cecil CAM, Walton E, Jaffee SR, et al. Neonatal dna methylation and early-onset conduct problems: A genome-wide, prospective study. First Posting Jun 9, 2017. Dev Psychopathol 2017 Pp No Pagination Specified Jun Dev Psychopathol. Published online 2017. doi:https://doi.org/10.1111/jcpp.12782

60. Cecil CAM, Walton E, Pingault J-B, et al. DRD4 methylation as a potential biomarker for physical aggression: An epigenome-wide, cross-tissue investigation. Am J Med Genet B Neuropsychiatr Genet. 2018;177(8):746-764. doi:10.1002/ajmg.b.32689

61. Hannon E, Dempster E, Viana J, et al. An integrated genetic-epigenetic analysis of schizophrenia: evidence for co-localization of genetic associations and differential DNA methylation. Genome Biol. 2016;17:176. doi:10.1186/s13059-016-1041-x 10.1186/s13059-016-1041-x [pii]

62. Mulder RH, Walton E, Neumann A, et al. Epigenomics of being bullied: changes in DNA methylation following bullying exposure. Epigenetics. 2020;15(6-7):750-764. doi:10.1080/15592294.2020.1719303

63. Roberts $\mathrm{S}$, Suderman $\mathrm{M}$, Zammit $\mathrm{S}$, et al. Longitudinal investigation of DNA methylation changes preceding adolescent psychotic experiences. Transl Psychiatry. 2019;9(1):1-12. doi:10.1038/s41398-019-0407-8

64. Phipson B, Maksimovic J, Oshlack A. missMethyl: an R package for analyzing data from Illumina's HumanMethylation450 platform. Bioinformatics. 2016;32(2):286-288. doi:10.1093/bioinformatics/btv560

65. Edgar RD, Jones MJ, Meaney MJ, Turecki G, Kobor MS. BECon: a tool for interpreting DNA methylation findings from blood in the context of brain. Transl Psychiatry. 2017;7(8):e1187. doi:10.1038/tp.2017.171 
66. Joubert BR, Felix JF, Yousefi P, et al. DNA Methylation in Newborns and Maternal Smoking in Pregnancy: Genome-wide Consortium Meta-analysis. Am J Hum Genet. 2016;98(4):680-696. doi:10.1016/j.ajhg.2016.02.019

67. Rzehak P, Saffery R, Reischl E, et al. Maternal Smoking during Pregnancy and DNA-Methylation in Children at Age 5.5 Years: Epigenome-Wide-Analysis in the European Childhood Obesity Project (CHOP)-Study. PLoS ONE. 2016;11(5). doi:10.1371/journal.pone.0155554

68. Colquhoun D. An investigation of the false discovery rate and the misinterpretation of p-values. $R$ Soc Open Sci. 2014;1(3):140216. doi:https://doi.org/10.1098/rsos.140216

69. Sullivan PF. Spurious Genetic Associations. Biol Psychiatry. 2007;61(10):1121-1126. doi:10.1016/j.biopsych.2006.11.010

70. Czamara D, Eraslan G, Page CM, et al. Integrated analysis of environmental and genetic influences on cord blood DNA methylation in new-borns. Nat Commun. 2019;10(1):1-18. doi:10.1038/s41467019-10461-0

71. Teh AL, Pan H, Chen L, et al. The effect of genotype and in utero environment on interindividual variation in neonate DNA methylomes. Genome Res. 2014;24(7):1064-1074. doi:10.1101/gr.171439.113

72. Shi L. Dock protein family in brain development and neurological disease. Commun Integr Biol. 2013;6(6):e26839. doi:10.4161/cib.26839

73. Agapite J, Albou L-P, Aleksander S, et al. Alliance of Genome Resources Portal: unified model organism research platform. Nucleic Acids Res. 2020;48(D1):D650-D658. doi:10.1093/nar/gkz813

74. Price AL, Weale ME, Patterson N, et al. Long-Range LD Can Confound Genome Scans in Admixed Populations. Am J Hum Genet. 2008;83(1):132-135. doi:10.1016/j.ajhg.2008.06.005

75. Shatz CJ. MHC Class I: An Unexpected Role in Neuronal Plasticity. Neuron. 2009;64(1):40-45. doi:10.1016/j.neuron.2009.09.044

76. Sobue A, Ito N, Nagai T, et al. Astroglial major histocompatibility complex class I following immune activation leads to behavioral and neuropathological changes. Glia. 2018;66(5):1034-1052. doi:10.1002/glia.23299

77. Murphy TM, Crawford B, Dempster EL, et al. Methylomic profiling of cortex samples from completed suicide cases implicates a role for PSORS1C3 in major depression and suicide. Transl Psychiatry. 2017;7(1):e989. doi:10.1038/tp.2016.249

78. Alkelai A, Lupoli S, Greenbaum L, et al. DOCK4 and CEACAM21 as novel schizophrenia candidate genes in the Jewish population. Int J Neuropsychopharmacol. 2012;15(4):459-469. doi:10.1017/S1461145711000903

79. Lee, Kim J-H, Song GG. Pathway analysis of a genome-wide association study in schizophrenia. Gene. 2013;525(1):107-115. doi:10.1016/j.gene.2013.04.014 
80. Zhang Y, You X, Li S, et al. Peripheral Blood Leukocyte RNA-Seq Identifies a Set of Genes Related to Abnormal Psychomotor Behavior Characteristics in Patients with Schizophrenia. Med Sci Monit Int Med J Exp Clin Res. 2020;26:e922426-1-e922426-31. doi:10.12659/MSM.922426

81. Glad CAM, Andersson-Assarsson JC, Berglund P, Bergthorsdottir R, Ragnarsson O, Johannsson G. Reduced DNA methylation and psychopathology following endogenous hypercortisolism - a genome-wide study. Sci Rep. 2017;7:44445. doi:10.1038/srep44445

82. Liang, Wang X, Zou M, et al. Family-based association study of ZNF533, DOCK4 and IMMP2L gene polymorphisms linked to autism in a northeastern Chinese Han population. J Zhejiang Univ Sci B. 2014;15(3):264-271. doi:10.1631/jzus.B1300133

83. Maestrini E, Pagnamenta AT, Lamb JA, et al. High-density SNP association study and copy number variation analysis of the AUTS1 and AUTS5 loci implicate the IMMP2L-DOCK4 gene region in autism susceptibility. Mol Psychiatry. 2010;15(9):954-968. doi:10.1038/mp.2009.34

84. Lee, Chang D-E, Yeom M, et al. Gene expression profiling in hypothalamus of immobilizationstressed mouse using cDNA microarray. Mol Brain Res. 2005;135(1):293-300. doi:10.1016/j.molbrainres.2004.11.016

85. Lisowski P, Juszczak GR, Goscik J, Wieczorek M, Zwierzchowski L, Swiergiel AH. Effect of chronic mild stress on hippocampal transcriptome in mice selected for high and low stress-induced analgesia and displaying different emotional behaviors. Eur Neuropsychopharmacol. 2011;21(1):45-62. doi:10.1016/j.euroneuro.2010.08.004

86. Papale LA, Madrid A, Li S, Alisch RS. Early-life stress links 5-hydroxymethylcytosine to anxietyrelated behaviors. Epigenetics. 2017;12(4):264-276. doi:10.1080/15592294.2017.1285986

87. Noro F, Gianfagna F, Gialluisi A, et al. ZBTB12 DNA methylation is associated with coagulationand inflammation-related blood cell parameters: findings from the Moli-family cohort. Clin Epigenetics. 2019;11(1):74. doi:10.1186/s13148-019-0665-6

88. White T, Muetzel RL, El Marroun H, et al. Paediatric population neuroimaging and the Generation R Study: the second wave. Eur J Epidemiol. 2018;33(1):99-125. doi:10.1007/s10654-017-0319-y

89. Illumina. Infinium MethylationEPIC Kit | Methylation profiling array for EWAS. Published 2020. Accessed July 6, 2020. https://www.illumina.com/products/by-type/microarray-kits/infiniummethylation-epic.html 
Maternal sensitivity and offspring DNA methylation 


\section{Supplementary Information:}

Epigenome-Wide Associations Between Observed Maternal Sensitivity and Offspring DNA Methylation:

A Population-Based Prospective Study in Children

\section{List of Supplementary Information (SI):}

Supplementary Information (SI):

SI1: Supplementary information on the methods

References: References for the supplementary information on the method

Supplementary Figures (SF):

SF1 A-C: BACON-corrected probe-level EWAS of the association between maternal sensitivity and DNAm

\section{Supplementary Tables (ST):}

ST1: Sample characteristics

ST2: Top sites from the probe-level EWAS with BACON-corrected estimates

ST3: Top regions from the regional-level EWAS

ST4: Candidate gene look-up

ST5: Gene ontology in-house results with MissMethyl validation

ST6: $\mathrm{mQTLs}$ associated with the CpGs within the significant DNAm regions

ST7: Associations between maternal sensitivity and DNA methylation at significant regions after adjustments for maternal education and psychopathology

ST8: Associations between maternal sensitivity and DNA methylation at significant regions after adjustments for baseline DNA methylation

ST9: Correlations of methylation values at birth with age 6 at significant regions

ST10: Gene ontology analysis based on the CpGs within the significant DNAm regions

ST11: BECon Brain-Blood Correlations 


\section{Text summary for the supplementary files:}

\section{Supplementary Information (SI):}

SI1.Here we describe the details of our sample, covariates, and the analyses performed (e.g. candidate gene look-up, adjustments for DNAm at birth, brain-blood correlations)

\section{Supplementary Figures (SF):}

SF1. Minimal bias is depicted in panel A, where adjusted and unadjusted test statistics approximately overlap. Deflation in the original EWAS is evident in panel B, where the observed $\mathrm{CpG} p$-values vary following BACON correction. After BACON-correction, a greater proportion of small as opposed to large p-values is present (panel C).

\section{Supplementary Tables (ST):}

ST1. All children in the present study are of Dutch ethnicity. An approximately equal proportion of males and females participated. Most mothers obtained a higher education qualification and never smoked during pregnancy.

ST2. None of the top $30 \mathrm{CpGs}$ identified in the probe-level EWAS surpassed genome-wide significance in the original EWAS. When BACON correction was applied, p-values decreased, with $\operatorname{cg} 25628898$, becoming statistically significant (estimate $=-0.008 ; \mathrm{SE}=0.002 ; \mathrm{p}=1.03 \mathrm{e}-$ 07)

ST3. The top 30 maternal sensitivity-DNAm associations are shown. The regional-level EWAS, after Bonferroni correction, revealed 13 regions significantly associated with maternal sensitivity.

ST4. Probe-level EWAS findings at four genes, previously identified in association with maternal care in humans, were leveraged. Gene-wide significance thresholds were calculated for each gene separately: $p<0.05$ / number of probes within the gene. There was no gene-wide significant probe. Only three probes reached nominal significance.

ST5. 148 significant pathways were identified as enriched by the in-house method, 39 of which were validated by the MissMethyl method (highlighted in green).

ST6. Twenty-two percent of the CpGs within the significant DNAm regions were significantly associated with one or more known SNPs. All associations were in cis.

ST7. Summary statistics before and after adjustments for maternal education and psychopathology, within a restricted sample with covariate data, are shown. After adjustments, estimates attenuated at approximately half of the regions.

ST8. Summary statistics before and after adjustments for DNA methylation at birth, within a restricted sample with DNAm at birth, are shown. After adjustments, estimates attenuated at 10 regions.

ST9. DNA methylation levels at birth and age six for our significant regions were generally moderate-to-strong: Rho $=0.43$. 
ST10. The follow-up gene ontology analysis, based on sites within our significant regions, identified 63 significant pathways, 33 of which were validated by MissMethyl.

ST11. We examined brain-blood correlations based on a publicly available database with information on DNAm levels across blood, Brodmann area (BA) 7, BA10 and BA20. Six regions presented half or more $\mathrm{CpGs}$ with correlations greater than the average value for all Infinium $450 \mathrm{~K}$ probes, in at least one brain tissue. 


\section{SI1. Supplementary Information on the Methods}

\section{Participants:}

Generation $\mathrm{R}$ was designed to shed light into environmental, genetic, and other pathways involved in (ab)normal development. For the purposes of this study, children within Generation $\mathrm{R}$ with data on maternal sensitivity (at three and/or four years) and DNAm (at six years) were selected. Maternal sensitivity assessments at ages three $(N=1247)$ and four $(N=752)$ years were both considered. This was done in line with previous literature ${ }^{1}$, due to the stability of the maternal sensitivity scores between age 3 and 4 years ${ }^{2}$, the temporality of these assessments, which both precede DNAm at age 6, and to maximize our sample size. Amongst children with maternal sensitivity data at either time point, 235 also had DNAm information at age six (i.e. the closest prospective DNAm assessment). Of note, this sample included 5 sibling-pairs and was the sample used for the main analyses. To ensure genetic relatedness did not impact results, one sibling per pair was later excluded in a sensitivity analysis. The excluded sibling presented the least covariate data.

In follow-up analyses, where additional adjustments for covariates were made, the main sample was further restricted to complete cases. For adjustments for maternal education and psychopathology, 223 children had data. For adjustments for DNAm levels at birth, 226 children had data.

\section{Covariates}

The main model in the epigenome-wide association study (EWAS) was adjusted for cell types, batch effects, sex, gestational age at birth, and maternal smoking during pregnancy. Further information on these variables is shown below.

\section{Cell-type and Batch effects}

Cell-type adjustments were performed, for analyses with DNAm at age six, for the following cell types: CD4 T lymphocytes, CD8 T lymphocytes, B lymphocytes, monocytes, natural killer cells. Of note, granulocyte cells were excluded due to multicollinearity. The sample plate was used as a measure of batch effects. This variable presented 17 levels.

Sex and gestational age at birth

Sex and gestational age were measured at child-birth. Sex was coded binarily into males and females. Gestational age at birth was measured continuously.

\section{Maternal smoking during pregnancy}

We analyzed maternal smoking during pregnancy as a three-level variable: $(i)$ did not smoke during pregnancy, (ii) smoked until pregnancy was known, (iii) smoked throughout pregnancy. This was based on previous work from Joubert et al. ${ }^{3}$ showing that sustained smoking throughout pregnancy has the strongest associations with offspring DNA methylation, with any smoking in pregnancy also showing significant associations, although not as strong. To ensure such variable was not subject to important bias, we additionally examined whether any of 
our hits (i.e. significant sites or sites within significant regions) overlapped with CpGs related to smoking, based on previous literature. Given the sample at hand, we used the Pregnancy and Childhood Epigenetics (PACE) consortium prenatal smoking exposure reference ${ }^{3}$. In this publication, 6074 genome-wide significant CpGs were identified in association with maternal smoking during pregnancy in cord blood. Additionally, since tissue- and age-specific effects might be present, we considered another EWAS of smoking carried out in childhood (age 5.5) in whole blood ${ }^{4}$, which identified five genome-wide significant probes.

\section{Maternal education and maternal psychopathology}

In follow-up analyses, we additionally adjusted for maternal education and maternal psychopathology. Maternal education was coded into low, medium, and high, respectively denoting primary, secondary, and tertiary education levels. Maternal psychopathology (postnatal: child age six months) was measured according to the Beck Symptoms Inventory (BSI) which presents information on the total maternal psychopathology symptoms.

\section{DNA methylation at birth}

In another follow-up analysis, additional adjustments for DNAm levels at birth were performed. This was done for top hits only. Covariates which are key to appropriately measure DNAm levels were also included: batch effects (measured by sample plate) and cell types (CD4 T lymphocytes, CD8T lymphocytes, B lymphocytes, monocytes, natural killer cells, and nucleated red blood cells - a cell type present only in cord blood).

\section{Statistical Analyses}

Regional-level EWAS

The dmrff approach, based on simulations, performs better compared to other regional methods in terms of false positive control, statistical power, and replicability across datasets ${ }^{5}$. Of note, the probe- and regional-level EWASs were rerun after one sibling per sibling-pair was excluded.

\section{Candidate gene look-up}

For the candidate gene look-up, we selected genes based on previous literature. We searched the PubMed and Google Scholar engines by using a combination of the following terms: "maternal care" or "maternal sensitivity" with "DNA methylation". Only studies in humans were considered. Review articles were excluded. Both epigenome-wide association studies (probe- and regional-level EWASs) as well as candidate gene studies were considered, yet, no EWAS had been performed to date on normative maternal care. Of the identified candidate gene studies, only those with statistically significant results were included, for a total of four publications ${ }^{6-9}$. Genes significantly related with maternal care/sensitivity included $N R 3 C 1, B D N F, S L C 6 A 4, O X T R$, and 11B-HSD2. Due to methylomic values not being available in our sample for $11 B-H S D 2$, such gene was excluded. Overall, four genes were selected based on previous literature.

\section{Gene Ontology: In-House method}


In this method, genes in the test list were tested in relation to pathway membership, with a logistic regression approach. We controlled for the number of probes annotated to each gene in the test list. The Gene Ontology website was utilized to obtain pathways. Genes annotated to parent terms were used too. A gene list was formed based on the probes associated with maternal sensitivity at a $p$-value threshold $<0.001$, based on the probe-level EWAS. The Illumina UCSC gene annotation permitted the annotation of probes to genes. Genes were considered if they were included in, at minimum, one gene ontology pathway and presented at least one annotated probe. Pathways were considered if including from 10 to 2000 genes. Once this method was used for all pathways, the significant ones with overlapping genes were retested. Associations were retested in all significant pathways, after adjusting for the most significant term. In case the associations at such pathways were no longer significant, the most significant pathway was considered as explaining the relationship. In such situation, pathways were grouped together. This process was repeated, with the next most significant pathway being adjusted for, till all pathways were considered as the most significant one or were identified as pertaining to a more significant pathway. A minimum of two genes was necessary for GO terms to be interpreted.

\section{Follow-up analyses}

Firstly, the influence of genetic factors on DNAm was examined, based on an openlyaccessible mQTL database. The database mQTL information was based on the results from the Accessible Resource for Integrative Epigenomics Studies (ARIES). The ARIES mQTL database includes data on the single nucleotide polymorphisms (SNPs) significantly affecting DNAm levels in cis or trans ( $p<1 \mathrm{e}^{-14}, 1 \mathrm{Mb}$ window), at several lifespan stages, based on the Infinium $450 \mathrm{~K}$ array. Here, we selected information for children, based on the results from a genome-wide complex trait conditional analysis.

Secondly, we adjusted for an additional set of parental confounders, maternal education and psychopathology, in a subsample of children with such information $(N=223)$. This was done on top hits only. To ensure estimate changes resulted from adjustments as opposed to the restriction to the subsample, firstly, we ran a multiple linear regression on our top hits, within the subsample of children with data on such confounders (Model A, $N=223$ ). This model was still unadjusted for maternal education and psychopathology. Subsequently, adjustments for maternal education and psychopathology were performed on top hits, within the subsample (Model B, $\mathrm{N}=$ 223 , adjusted model), with a multiple linear regression. The newly-obtained site summary statistics for both models were then inputted in DMRff, where the function dmrff.stats enables the recalculation of the statistics per DNAm region. The percent estimate change was then calculated ((estimate after adjustments - estimate before adjustments) / estimate before adjustments $* 100)$.

The same procedure was employed for adjustments for DNAm levels at birth. Therefore, a multiple linear regression where, for each site, its own DNAm levels at baseline were used as covariates, was tested in association with maternal sensitivity: site DNAm at six $\sim$ maternal sensitivity + main set of covariates + site DNAm at birth (Model $\mathrm{B}, N=226$ ). This was compared to a restricted unadjusted model (Model A, $N=226$ ). Site statistics were inputted in dmrff.stats to obtain regional-level statistics.

Lastly, the BECon online tool used here includes information on tissue concordance between DNAm in blood and Brodmann Areas (BA) seven, 10 and 20, based on brain postmortem samples from 16 subjects. 



\section{References:}

1. Kok R, Thijssen S, Bakermans-Kranenburg MJ, et al. Normal Variation in Early Parental Sensitivity Predicts Child Structural Brain Development. J Am Acad Child Adolesc Psychiatry. 2015;54(10):824-831.e1. doi:10.1016/j.jaac.2015.07.009

2. Kok R, Linting M, Bakermans-Kranenburg MJ, et al. Maternal Sensitivity and Internalizing Problems: Evidence from Two Longitudinal Studies in Early Childhood. Child Psychiatry Hum Dev. 2013;44(6):751-765. doi:10.1007/s10578-013-0369-7

3. Joubert BR, Felix JF, Yousefi P, et al. DNA Methylation in Newborns and Maternal Smoking in Pregnancy: Genome-wide Consortium Meta-analysis. Am J Hum Genet. 2016;98(4):680-696. doi:10.1016/j.ajhg.2016.02.019

4. Rzehak P, Saffery R, Reischl E, et al. Maternal Smoking during Pregnancy and DNAMethylation in Children at Age 5.5 Years: Epigenome-Wide-Analysis in the European Childhood Obesity Project (CHOP)-Study. PLoS ONE. 2016;11(5). doi:10.1371/journal.pone.0155554

5. Suderman M, Staley JR, French R, Arathimos R, Simpkin A, Tilling K. Dmrff: Identifying Differentially Methylated Regions Efficiently with Power and Control. Bioinformatics; 2018. doi:10.1101/508556

6. Bosmans G, Young JF, Hankin BL. NR3C1 methylation as a moderator of the effects of maternal support and stress on insecure attachment development. Dev Psychol. 2018;54(1):29-38. doi:10.1037/dev0000422

7. Conradt E, Hawes K, Guerin D, et al. The Contributions of Maternal Sensitivity and Maternal Depressive Symptoms to Epigenetic Processes and Neuroendocrine Functioning. Child Dev. 2016;87(1):73-85. doi:10.1111/cdev.12483

8. Provenzi L, Fumagalli M, Giorda R, et al. Maternal Sensitivity Buffers the Association between SLC6A4 Methylation and Socio-Emotional Stress Response in 3-Month-Old Full Term, but not very Preterm Infants. Front Psychiatry. 2017;8. doi:10.3389/fpsyt.2017.00171

9. Unternaehrer E, Meyer AH, Burkhardt SCA, et al. Childhood maternal care is associated with DNA methylation of the genes for brain-derived neurotrophic factor ( BDNF) and oxytocin receptor ( OXTR ) in peripheral blood cells in adult men and women. Stress. 2015;18(4):451-461. doi:10.3109/10253890.2015.1038992 


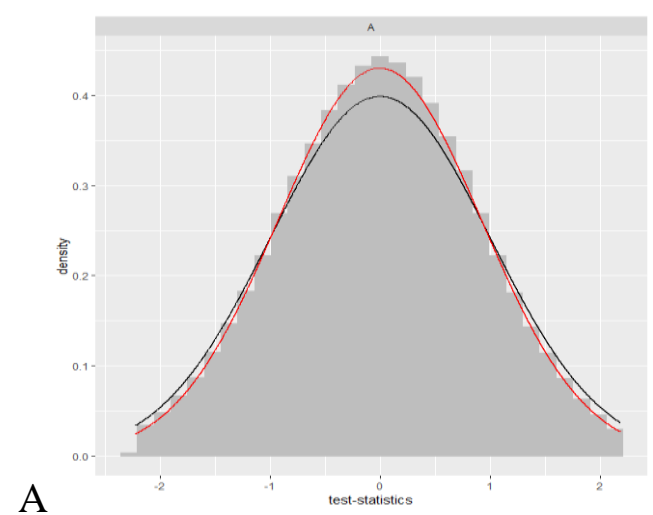

B

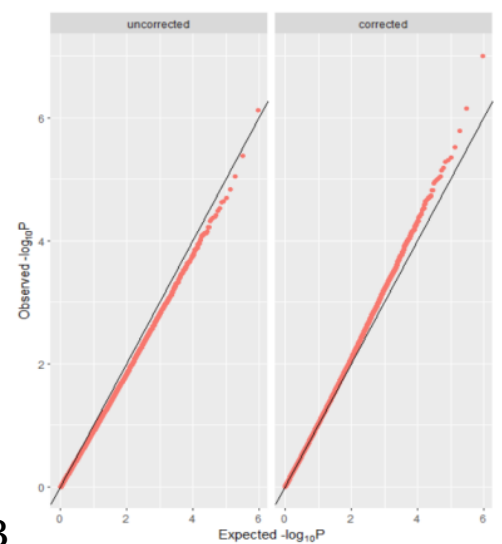

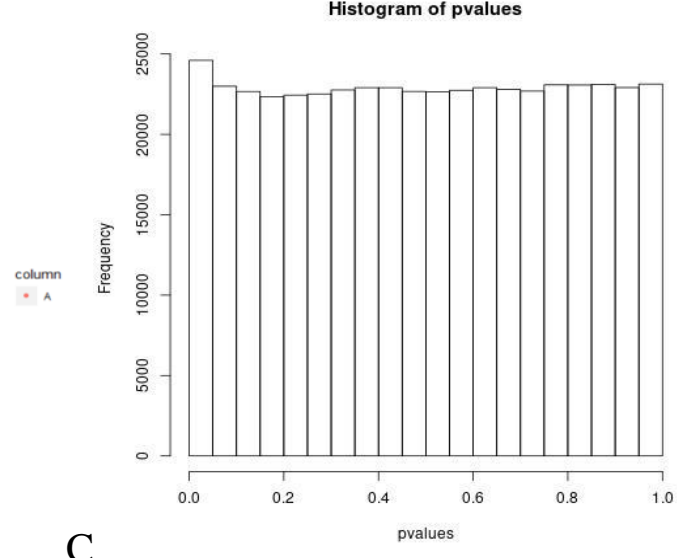

$\mathrm{C}$

Supplementary Figure 1 A-C.

$B A C O N$-corrected probe-level EWAS of the association between maternal sensitivity and DNAm

Note. Panel A shows the test statistic histogram. This indicates minimal bias, as shown by the proximity of the black and red lines. Panel B depicts uncorrected and BACON-corrected QQ-plots. The uncorrected QQ-plot is from the main EWAS and shows no significant associations. The BACON-corrected QQ-plot suggests that values were originally deflated in the EWAS and that, after corrections, associations are present. Panel C is a histogram of $p$-values after BACON-correction, showing that there is a greater proportion of sites with low $p$-values compared to the proportion of sites with higher $p$-values, further suggesting that associations of maternal sensitivity with DNAm are present. 
ST1. Sample characteristics

Child and maternal characteristics

Percentage/Mean

Child Characteristics

Sex - females

$49 \%$

Child Ethnicity - Dutch

$100 \%$

\section{Maternal Characteristics}

$\begin{array}{ll}\text { Observed maternal sensitivity } & 0.05\end{array}$

Maternal Education*

Primary education

$8 \%$

Secondary education

$21 \%$

Higher education

$71 \%$

Gestational age at birth

40.31

Maternal prenatal smoking

Never smoked

$75 \%$

Quit when pregnancy known

$11 \%$

Continued during pregnancy

$14 \%$

Maternal psychopathology*

0.15

Note. $\%=$ percentage

*Information was available only for a subsample $(\mathrm{n}=223)$ 
ST2. Top sites from the probe-level EWAS with BACON-corrected estimates

\begin{tabular}{|c|c|c|c|c|c|c|}
\hline CpG & $\begin{array}{l}\text { EWAS T- } \\
\text { statistic }\end{array}$ & $\begin{array}{l}\text { EWAS P- } \\
\text { value }\end{array}$ & $\begin{array}{c}\text { EWAS } \\
\text { Estimate }\end{array}$ & $\begin{array}{c}\text { EWAS Standard } \\
\text { Error }\end{array}$ & $\begin{array}{l}\text { Bacon T- } \\
\text { statistic }\end{array}$ & $\begin{array}{c}\text { Bacon P- } \\
\text { value }\end{array}$ \\
\hline $\operatorname{cg} 25628898$ & -4.93 & $1.7 \mathrm{E}-06$ & -0.01 & 0.00 & -5.32 & 0.000 \\
\hline $\operatorname{cg} 00808563$ & -4.62 & 6.7E-06 & -0.01 & 0.00 & -4.99 & 0.000 \\
\hline $\operatorname{cg} 27541515$ & 4.43 & $1.5 \mathrm{E}-05$ & 0.01 & 0.00 & 4.79 & 0.000 \\
\hline $\operatorname{cg} 01567825$ & -4.34 & $2.2 \mathrm{E}-05$ & -0.02 & 0.00 & -4.69 & 0.000 \\
\hline $\operatorname{cg} 26554505$ & 4.26 & $3.1 \mathrm{E}-05$ & 0.00 & 0.00 & 4.60 & 0.000 \\
\hline $\operatorname{cg} 21457839$ & 4.20 & $3.9 \mathrm{E}-05$ & 0.00 & 0.00 & 4.54 & 0.000 \\
\hline $\operatorname{cg} 05637265$ & -4.19 & $4.2 \mathrm{E}-05$ & -0.01 & 0.00 & -4.52 & 0.000 \\
\hline $\operatorname{cg} 07439474$ & 4.17 & 4.4E-05 & 0.00 & 0.00 & 4.51 & 0.000 \\
\hline $\operatorname{cg} 02276600$ & 4.17 & $4.4 \mathrm{E}-05$ & 0.01 & 0.00 & 4.51 & 0.000 \\
\hline $\operatorname{cg} 01200177$ & 4.17 & $4.5 \mathrm{E}-05$ & 0.02 & 0.01 & 4.51 & 0.000 \\
\hline $\operatorname{cg} 04604420$ & -4.16 & 4.7E-05 & -0.01 & 0.00 & -4.49 & 0.000 \\
\hline $\operatorname{cg} 05935283$ & 4.16 & 4.7E-05 & 0.00 & 0.00 & 4.49 & 0.000 \\
\hline $\operatorname{cg} 00079764$ & 4.08 & $6.4 \mathrm{E}-05$ & 0.01 & 0.00 & 4.41 & 0.000 \\
\hline $\operatorname{cg} 09678349$ & -4.03 & $7.8 \mathrm{E}-05$ & -0.02 & 0.01 & -4.35 & 0.000 \\
\hline $\operatorname{cg} 14012059$ & -3.99 & $9.1 \mathrm{E}-05$ & -0.02 & 0.00 & -4.31 & 0.000 \\
\hline $\operatorname{cg} 25623347$ & -3.98 & $9.3 \mathrm{E}-05$ & -0.01 & 0.00 & -4.30 & 0.000 \\
\hline $\operatorname{cg} 02328660$ & 3.98 & $9.4 \mathrm{E}-05$ & 0.00 & 0.00 & 4.31 & 0.000 \\
\hline $\operatorname{cg} 19755714$ & 3.98 & $9.5 \mathrm{E}-05$ & 0.01 & 0.00 & 4.30 & 0.000 \\
\hline $\operatorname{cg} 12441928$ & -3.97 & $1.0 \mathrm{E}-04$ & 0.00 & 0.00 & -4.28 & 0.000 \\
\hline $\operatorname{cg} 03113916$ & -3.94 & $1.1 \mathrm{E}-04$ & -0.01 & 0.00 & -4.26 & 0.000 \\
\hline $\operatorname{cg} 03810365$ & 3.94 & $1.1 \mathrm{E}-04$ & 0.01 & 0.00 & 4.26 & 0.000 \\
\hline $\operatorname{cg} 09086615$ & -3.93 & $1.2 \mathrm{E}-04$ & -0.01 & 0.00 & -4.24 & 0.000 \\
\hline $\operatorname{cg} 10066481$ & -3.92 & $1.2 \mathrm{E}-04$ & -0.01 & 0.00 & -4.23 & 0.000 \\
\hline $\operatorname{cg} 10319073$ & -3.91 & $1.2 \mathrm{E}-04$ & -0.01 & 0.00 & -4.23 & 0.000 \\
\hline cg20093139 & 3.91 & $1.2 \mathrm{E}-04$ & 0.01 & 0.00 & 4.23 & 0.000 \\
\hline $\operatorname{cg} 22798223$ & -3.91 & $1.3 \mathrm{E}-04$ & 0.00 & 0.00 & -4.22 & 0.000 \\
\hline $\operatorname{cg} 24618910$ & 3.90 & $1.3 \mathrm{E}-04$ & 0.00 & 0.00 & 4.22 & 0.000 \\
\hline $\operatorname{cg} 20959907$ & -3.88 & $1.4 \mathrm{E}-04$ & -0.02 & 0.00 & -4.19 & 0.000 \\
\hline $\operatorname{cg} 15871766$ & -3.87 & $1.5 \mathrm{E}-04$ & -0.02 & 0.01 & -4.18 & 0.000 \\
\hline
\end{tabular}


ST3. Top regions from the regional-level EWAS

\begin{tabular}{cccccc}
\hline Location & $\begin{array}{c}\text { N } \\
\text { CpGs }\end{array}$ & Estimate & Standard Error & P-value & $\begin{array}{c}\text { Adj. P- } \\
\text { value }\end{array}$ \\
\hline chr2:241458886-241460002 & 8 & -0.36 & 0.04 & $1.17 \mathrm{E}-17$ & $5.61 \mathrm{E}-12$ \\
chr6:30039027-30039600 & 22 & -0.23 & 0.03 & $5.03 \mathrm{E}-16$ & $2.42 \mathrm{E}-10$ \\
chr6:33282879-33283184 & 17 & -0.21 & 0.03 & $1.83 \mathrm{E}-15$ & $8.77 \mathrm{E}-10$ \\
chr2:21266727-21267334 & 10 & -0.30 & 0.04 & $2.83 \mathrm{E}-14$ & $1.36 \mathrm{E}-08$ \\
chr2:3642629-3642867 & 6 & -0.87 & 0.14 & $9.80 \mathrm{E}-11$ & $4.71 \mathrm{E}-05$ \\
chr17:6797034-6797771 & 6 & -0.57 & 0.09 & $1.00 \mathrm{E}-10$ & $4.80 \mathrm{E}-05$ \\
chr7:111368367-111368847 & 4 & -0.82 & 0.13 & $1.02 \mathrm{E}-10$ & $4.90 \mathrm{E}-05$ \\
chr6:32145383-32146595 & 27 & 0.05 & 0.01 & $3.55 \mathrm{E}-10$ & $1.71 \mathrm{E}-04$ \\
chr7:158749953-158751591 & 8 & 0.56 & 0.09 & $4.80 \mathrm{E}-10$ & $2.31 \mathrm{E}-04$ \\
chr6:33280149-33280436 & 9 & -0.28 & 0.05 & $8.89 \mathrm{E}-10$ & $4.27 \mathrm{E}-04$ \\
chr6:31867757-31868169 & 19 & -0.10 & 0.02 & $2.35 \mathrm{E}-08$ & $1.13 \mathrm{E}-02$ \\
chr4:147164778-147165097 & 4 & 0.43 & 0.08 & $2.53 \mathrm{E}-08$ & $1.21 \mathrm{E}-02$ \\
chr1:11714218-11714254 & 3 & -0.44 & 0.08 & $5.82 \mathrm{E}-08$ & $2.80 \mathrm{E}-02$ \\
chr4:1243980-1244086 & 6 & 1.04 & 0.20 & $1.19 \mathrm{E}-07$ & $5.70 \mathrm{E}-02$ \\
chr7:158551048-158551361 & 4 & -0.58 & 0.11 & $1.47 \mathrm{E}-07$ & $7.07 \mathrm{E}-02$ \\
chr20:57225195-57225678 & 2 & 0.12 & 0.02 & $1.65 \mathrm{E}-07$ & $7.92 \mathrm{E}-02$ \\
chr11:70672365-70672858 & 7 & -0.28 & 0.05 & $2.27 \mathrm{E}-07$ & $1.09 \mathrm{E}-01$ \\
chr7:63505638-63505871 & 6 & 0.84 & 0.16 & $2.56 \mathrm{E}-07$ & $1.23 \mathrm{E}-01$ \\
chr20:36148615-36148928 & 14 & -0.09 & 0.02 & $2.99 \mathrm{E}-07$ & $1.43 \mathrm{E}-01$ \\
chr2:128616082-128616167 & 2 & 1.07 & 0.21 & $4.00 \mathrm{E}-07$ & $1.92 \mathrm{E}-01$ \\
chr6:33245619-33246105 & 17 & -0.10 & 0.02 & $4.75 \mathrm{E}-07$ & $2.28 \mathrm{E}-01$ \\
chr10:82295394-82296191 & 6 & 0.45 & 0.09 & $5.63 \mathrm{E}-07$ & $2.71 \mathrm{E}-01$ \\
chr2:20870087-20871002 & 5 & -1.42 & 0.29 & $8.51 \mathrm{E}-07$ & $4.09 \mathrm{E}-01$ \\
chr6:31856617-31856773 & 4 & -0.39 & 0.08 & $9.10 \mathrm{E}-07$ & $4.37 \mathrm{E}-01$ \\
chr7:44349704-44349955 & 3 & 0.91 & 0.19 & $1.15 \mathrm{E}-06$ & $5.52 \mathrm{E}-01$ \\
chr19:57702479-57702772 & 6 & 0.23 & 0.05 & $1.19 \mathrm{E}-06$ & $5.72 \mathrm{E}-01$ \\
chr7:6979239-6979488 & 2 & -0.22 & 0.05 & $1.34 \mathrm{E}-06$ & $6.42 \mathrm{E}-01$ \\
chr12:52404134-52404422 & 4 & 0.29 & 0.06 & $1.42 \mathrm{E}-06$ & $6.82 \mathrm{E}-01$ \\
\hline
\end{tabular}

Note. adj. $=$ adjusted; $\mathrm{N}=$ number. 
ST4. Candidate gene look-up

\begin{tabular}{|c|c|c|c|c|c|c|c|c|c|}
\hline Gene & Location & CPG.Labels & estimate & std.error & T.statistic & P.value & Genome_wide_sign & Gene_wide_sign & Nominal_sign \\
\hline BDNF & chr11:27744816 & $\operatorname{cg} 18867480$ & -0.003 & 0.002 & -1.63 & 0.105 & No & No & No \\
\hline BDNF & chr11:27744363 & $\operatorname{cg} 11718030$ & -0.003 & 0.003 & -0.95 & 0.342 & No & No & No \\
\hline BDNF & chr11:27744049 & $\operatorname{cg} 15462887$ & 0.002 & 0.003 & 0.72 & 0.475 & No & No & No \\
\hline BDNF & chr11:27744490 & $\operatorname{cg} 06046431$ & 0.000 & 0.001 & -0.50 & 0.619 & No & No & No \\
\hline BDNF & chr11:27744557 & $\operatorname{cg} 10022526$ & -0.001 & 0.002 & -0.50 & 0.620 & No & No & No \\
\hline BDNF & chr11:27744759 & $\operatorname{cg} 24249411$ & -0.001 & 0.003 & -0.35 & 0.729 & No & No & No \\
\hline BDNF & chr11:27743619 & $\operatorname{cg} 03167496$ & -0.002 & 0.002 & -1.58 & 0.115 & No & No & No \\
\hline BDNF & chr11:27743664 & $\operatorname{cg} 25457956$ & 0.001 & 0.002 & 0.68 & 0.494 & No & No & No \\
\hline BDNF & chr11:27743651 & $\operatorname{cg} 25381667$ & -0.001 & 0.001 & -0.63 & 0.532 & No & No & No \\
\hline BDNF & chr11:27743648 & $\operatorname{cg} 14589148$ & -0.001 & 0.002 & -0.56 & 0.577 & No & No & No \\
\hline BDNF & chr11:27742832 & cg07704699 & 0.001 & 0.007 & 0.21 & 0.834 & No & No & No \\
\hline BDNF & chr11:27743258 & $\operatorname{cg} 27351358$ & -0.004 & 0.002 & -1.63 & 0.105 & No & No & No \\
\hline BDNF & chr11:27740161 & $\operatorname{cg} 21010859$ & -0.002 & 0.001 & -1.58 & 0.115 & No & No & No \\
\hline BDNF & chr11:27740813 & $\operatorname{cg} 13974632$ & 0.004 & 0.003 & 1.45 & 0.149 & No & No & No \\
\hline BDNF & chr11:27739827 & $\operatorname{cg} 17413943$ & 0.004 & 0.003 & 1.36 & 0.175 & No & No & No \\
\hline BDNF & $\operatorname{chr11:27743348}$ & $\operatorname{cg} 02527472$ & 0.002 & 0.002 & 1.21 & 0.226 & No & No & No \\
\hline BDNF & chr11:27742365 & $\operatorname{cg} 12448003$ & -0.001 & 0.002 & -0.76 & 0.449 & No & No & No \\
\hline BDNF & chr11:27742355 & $\operatorname{cg} 01225698$ & 0.003 & 0.003 & 0.76 & 0.451 & No & No & No \\
\hline BDNF & chr11:27742369 & $\operatorname{cg} 06684850$ & -0.003 & 0.004 & -0.72 & 0.475 & No & No & No \\
\hline BDNF & chr11:27743476 & $\operatorname{cg} 01642653$ & 0.001 & 0.002 & 0.63 & 0.528 & No & No & No \\
\hline BDNF & chr11:27740078 & $\operatorname{cg} 05818894$ & 0.001 & 0.002 & 0.49 & 0.625 & No & No & No \\
\hline BDNF & chr11:27742454 & $\operatorname{cg} 04106006$ & 0.003 & 0.007 & 0.41 & 0.684 & No & No & No \\
\hline BDNF & chr11:27740876 & $\operatorname{cg} 05733135$ & -0.001 & 0.002 & -0.37 & 0.710 & No & No & No \\
\hline BDNF & chr11:27732958 & $\operatorname{cg} 11806762$ & -0.001 & 0.005 & -0.28 & 0.779 & No & No & No \\
\hline BDNF & chr11:27743580 & $\operatorname{cg} 16257091$ & -0.001 & 0.006 & -0.22 & 0.824 & No & No & No \\
\hline BDNF & chr11:27740495 & $\operatorname{cg} 04481212$ & 0.000 & 0.002 & 0.12 & 0.907 & No & No & No \\
\hline BDNF & chr11:27742435 & $\operatorname{cg} 10635145$ & 0.001 & 0.007 & 0.10 & 0.918 & No & No & No \\
\hline BDNF & chr11:27741077 & $\operatorname{cg} 22043168$ & 0.002 & 0.002 & 0.95 & 0.341 & No & No & No \\
\hline BDNF & chr11:27741916 & $\operatorname{cg} 24650785$ & 0.002 & 0.003 & 0.72 & 0.470 & No & No & No \\
\hline BDNF & chr11:27742138 & $\operatorname{cg} 25412831$ & -0.004 & 0.003 & -1.49 & 0.139 & No & No & No \\
\hline BDNF & $\operatorname{chr11:27742060}$ & $\operatorname{cg} 26949694$ & 0.002 & 0.003 & 0.63 & 0.530 & No & No & No \\
\hline BDNF & chr11:27742219 & $\operatorname{cg} 06816235$ & 0.000 & 0.002 & -0.14 & 0.885 & No & No & No \\
\hline BDNF & $\operatorname{chr11:27723290}$ & $\operatorname{cg} 26840770$ & 0.005 & 0.002 & 2.36 & 0.019 & No & No & Yes \\
\hline BDNF & chr11:27723214 & $\operatorname{cg} 23497217$ & -0.005 & 0.003 & -1.82 & 0.070 & No & No & No \\
\hline BDNF & chr11:27722722 & $\operatorname{cg} 03747251$ & -0.010 & 0.006 & -1.58 & 0.116 & No & No & No \\
\hline
\end{tabular}




\begin{tabular}{|c|c|c|c|c|c|c|c|c|c|}
\hline BDNF & $\operatorname{chr11:27723218}$ & $\operatorname{cg} 05218375$ & 0.004 & 0.003 & 1.21 & 0.228 & No & No & No \\
\hline BDNF & chr11:27722774 & $\operatorname{cg} 15914769$ & 0.001 & 0.001 & 1.18 & 0.241 & No & No & No \\
\hline BDNF & chr11:27723237 & $\operatorname{cg} 06991510$ & -0.001 & 0.001 & -0.64 & 0.525 & No & No & No \\
\hline BDNF & chr11:27723190 & $\operatorname{cg} 15688670$ & 0.000 & 0.001 & 0.38 & 0.705 & No & No & No \\
\hline BDNF & chr11:27723409 & $\operatorname{cg} 24065044$ & 0.000 & 0.003 & 0.16 & 0.869 & No & No & No \\
\hline BDNF & chr11:27723245 & $\operatorname{cg} 24377657$ & 0.000 & 0.003 & 0.13 & 0.896 & No & No & No \\
\hline BDNF & chr11:27723385 & $\operatorname{cg} 01636003$ & 0.000 & 0.002 & 0.04 & 0.967 & No & No & No \\
\hline BDNF & chr11:27723075 & $\operatorname{cg} 20340655$ & -0.002 & 0.001 & -1.56 & 0.120 & No & No & No \\
\hline BDNF & $\operatorname{chr11:27722971}$ & $\operatorname{cg} 09606766$ & 0.001 & 0.001 & 0.90 & 0.370 & No & No & No \\
\hline BDNF & chr11:27723128 & $\operatorname{cg} 11241206$ & 0.000 & 0.001 & 0.27 & 0.789 & No & No & No \\
\hline BDNF & chr11:27722889 & $\operatorname{cg} 04672351$ & 0.000 & 0.002 & 0.19 & 0.848 & No & No & No \\
\hline BDNF & chr11:27720709 & $\operatorname{cg} 09492354$ & 0.001 & 0.001 & 1.78 & 0.077 & No & No & No \\
\hline BDNF & chr11:27721277 & $\operatorname{cg} 26057780$ & -0.002 & 0.001 & -1.49 & 0.137 & No & No & No \\
\hline BDNF & chr11:27722037 & $\operatorname{cg} 23947039$ & -0.002 & 0.001 & -1.46 & 0.147 & No & No & No \\
\hline BDNF & $\operatorname{chr11:27718978}$ & cg20108357 & -0.006 & 0.005 & -1.34 & 0.181 & No & No & No \\
\hline BDNF & chr11:27722066 & $\operatorname{cg} 18117895$ & -0.001 & 0.001 & -1.25 & 0.212 & No & No & No \\
\hline BDNF & chr11:27701991 & $\operatorname{cg} 18595174$ & -0.004 & 0.003 & -1.15 & 0.251 & No & No & No \\
\hline BDNF & chr11:27721668 & cg20954537 & 0.001 & 0.002 & 0.96 & 0.339 & No & No & No \\
\hline BDNF & $\operatorname{chr11:27722636}$ & $\operatorname{cg} 08362738$ & 0.001 & 0.001 & 0.88 & 0.379 & No & No & No \\
\hline BDNF & chr11:27722638 & $\operatorname{cg} 25328597$ & 0.001 & 0.002 & 0.78 & 0.434 & No & No & No \\
\hline BDNF & chr11:27722620 & $\operatorname{cg} 15710245$ & 0.002 & 0.004 & 0.66 & 0.511 & No & No & No \\
\hline BDNF & chr11:27721270 & $\operatorname{cg} 15313332$ & -0.001 & 0.001 & -0.50 & 0.620 & No & No & No \\
\hline BDNF & chr11:27722617 & $\operatorname{cg} 03984780$ & 0.001 & 0.003 & 0.42 & 0.676 & No & No & No \\
\hline BDNF & chr11:27721280 & $\operatorname{cg} 10558494$ & 0.001 & 0.002 & 0.33 & 0.740 & No & No & No \\
\hline BDNF & $\operatorname{chr11:27721350}$ & $\operatorname{cg} 06260077$ & -0.001 & 0.003 & -0.19 & 0.847 & No & No & No \\
\hline BDNF & $\operatorname{chr11:27721222}$ & $\operatorname{cg} 25962210$ & 0.000 & 0.002 & -0.17 & 0.867 & No & No & No \\
\hline BDNF & $\operatorname{chr11:27722063}$ & $\operatorname{cg} 00298481$ & 0.000 & 0.001 & -0.03 & 0.977 & No & No & No \\
\hline BDNF & $\operatorname{chr11:27721088}$ & $\operatorname{cg} 27193031$ & 0.000 & 0.002 & 0.25 & 0.801 & No & No & No \\
\hline BDNF & $\operatorname{chr} 11: 27722523$ & $\operatorname{cg} 07159484$ & 0.000 & 0.002 & -0.06 & 0.949 & No & No & No \\
\hline BDNF & chr11:27722549 & $\operatorname{cg} 06025631$ & 0.001 & 0.001 & 1.03 & 0.302 & No & No & No \\
\hline BDNF & $\operatorname{chr} 11: 27677125$ & $\operatorname{cg} 06979684$ & -0.006 & 0.004 & -1.64 & 0.103 & No & No & No \\
\hline BDNF & $\operatorname{chr} 11: 27680480$ & $\operatorname{cg} 05189570$ & -0.002 & 0.002 & -0.98 & 0.330 & No & No & No \\
\hline BDNF & chr11:27679729 & $\operatorname{cg} 23426002$ & 0.002 & 0.002 & 1.17 & 0.242 & No & No & No \\
\hline BDNF & chr11:27679469 & $\operatorname{cg} 01418645$ & -0.001 & 0.002 & -0.71 & 0.478 & No & No & No \\
\hline BDNF & $\operatorname{chr11:27681475}$ & $\operatorname{cg} 07238832$ & 0.001 & 0.002 & 0.44 & 0.662 & No & No & No \\
\hline BDNF & chr11:27679632 & $\operatorname{cg} 08388004$ & 0.000 & 0.002 & -0.01 & 0.988 & No & No & No \\
\hline BDNF & chr11:27696004 & $\operatorname{cg} 18354203$ & 0.001 & 0.005 & 0.30 & 0.762 & No & No & No \\
\hline
\end{tabular}




\begin{tabular}{|c|c|c|c|c|c|c|c|c|c|}
\hline BDNF & chr11:27683959 & $\operatorname{cg} 14291693$ & -0.004 & 0.004 & -1.08 & 0.281 & No & No & No \\
\hline BDNF & $\operatorname{chr11:27695210}$ & $\operatorname{cg} 15014679$ & 0.000 & 0.004 & -0.09 & 0.929 & No & No & No \\
\hline $\mathrm{NR} 3 \mathrm{C} 1$ & chr5:142786405 & $\operatorname{cg} 27345592$ & 0.005 & 0.002 & 1.86 & 0.064 & No & No & No \\
\hline $\mathrm{NR} 3 \mathrm{C} 1$ & chr5:142815469 & $\operatorname{cg} 12466613$ & 0.006 & 0.004 & 1.73 & 0.085 & No & No & No \\
\hline $\mathrm{NR} 3 \mathrm{C} 1$ & chr5:142815463 & $\operatorname{cg} 07589972$ & 0.001 & 0.002 & 0.41 & 0.683 & No & No & No \\
\hline $\mathrm{NR} 3 \mathrm{C} 1$ & chr5:142788776 & $\operatorname{cg} 07528216$ & 0.001 & 0.002 & 0.38 & 0.706 & No & No & No \\
\hline $\mathrm{NR} 3 \mathrm{C} 1$ & chr5:142785172 & $\operatorname{cg} 24026230$ & 0.002 & 0.001 & 1.88 & 0.061 & No & No & No \\
\hline $\mathrm{NR} 3 \mathrm{C} 1$ & chr5:142784982 & $\operatorname{cg} 14558428$ & 0.000 & 0.001 & 0.62 & 0.534 & No & No & No \\
\hline $\mathrm{NR} 3 \mathrm{C} 1$ & chr5:142785258 & $\operatorname{cg} 13648501$ & 0.002 & 0.003 & 0.55 & 0.584 & No & No & No \\
\hline $\mathrm{NR} 3 \mathrm{C} 1$ & chr5:142814827 & $\operatorname{cg} 08818984$ & 0.003 & 0.002 & 1.32 & 0.189 & No & No & No \\
\hline $\mathrm{NR} 3 \mathrm{C} 1$ & chr5:142814934 & $\operatorname{cg} 26720913$ & 0.002 & 0.002 & 1.05 & 0.293 & No & No & No \\
\hline $\mathrm{NR} 3 \mathrm{C} 1$ & chr5:142780254 & $\operatorname{cg} 17342132$ & 0.005 & 0.002 & 2.15 & 0.033 & No & No & Yes \\
\hline $\mathrm{NR} 3 \mathrm{C} 1$ & chr5:142658828 & $\operatorname{cg} 23273257$ & 0.003 & 0.002 & 1.79 & 0.074 & No & No & No \\
\hline $\mathrm{NR} 3 \mathrm{C} 1$ & chr5:142784222 & $\operatorname{cg} 26464411$ & 0.001 & 0.001 & 1.20 & 0.233 & No & No & No \\
\hline $\mathrm{NR} 3 \mathrm{C} 1$ & chr5:142781532 & $\operatorname{cg} 18998365$ & 0.006 & 0.005 & 1.19 & 0.234 & No & No & No \\
\hline $\mathrm{NR} 3 \mathrm{C} 1$ & chr5:142782415 & $\operatorname{cg} 17617527$ & 0.001 & 0.001 & 1.09 & 0.275 & No & No & No \\
\hline $\mathrm{NR} 3 \mathrm{C} 1$ & chr5:142783385 & $\operatorname{cg} 18019515$ & -0.001 & 0.001 & -1.01 & 0.312 & No & No & No \\
\hline $\mathrm{NR} 3 \mathrm{C} 1$ & chr5:142783639 & $\operatorname{cg} 15645634$ & -0.001 & 0.001 & -0.90 & 0.368 & No & No & No \\
\hline $\mathrm{NR} 3 \mathrm{C} 1$ & chr5:142784323 & $\operatorname{cg} 06968181$ & -0.002 & 0.002 & -0.88 & 0.379 & No & No & No \\
\hline $\mathrm{NR} 3 \mathrm{C} 1$ & chr5:142729913 & $\operatorname{cg} 03857453$ & -0.002 & 0.003 & -0.76 & 0.448 & No & No & No \\
\hline $\mathrm{NR} 3 \mathrm{C} 1$ & chr5:142776274 & $\operatorname{cg} 27107893$ & -0.004 & 0.006 & -0.75 & 0.456 & No & No & No \\
\hline $\mathrm{NR} 3 \mathrm{C} 1$ & chr5:142783569 & $\operatorname{cg} 17860381$ & 0.000 & 0.001 & -0.66 & 0.510 & No & No & No \\
\hline $\mathrm{NR} 3 \mathrm{C} 1$ & chr5:142784382 & $\operatorname{cg} 18849621$ & 0.002 & 0.002 & 0.63 & 0.530 & No & No & No \\
\hline $\mathrm{NR} 3 \mathrm{C} 1$ & chr5:142780693 & $\operatorname{cg} 08845721$ & 0.001 & 0.003 & 0.48 & 0.632 & No & No & No \\
\hline $\mathrm{NR} 3 \mathrm{C} 1$ & chr5:142781498 & $\operatorname{cg} 07733851$ & 0.002 & 0.005 & 0.47 & 0.640 & No & No & No \\
\hline $\mathrm{NR} 3 \mathrm{C} 1$ & chr5:142740314 & $\operatorname{cg} 18484679$ & -0.001 & 0.003 & -0.45 & 0.651 & No & No & No \\
\hline $\mathrm{NR} 3 \mathrm{C} 1$ & chr5:142782072 & $\operatorname{cg} 06521673$ & 0.001 & 0.001 & 0.45 & 0.652 & No & No & No \\
\hline $\mathrm{NR} 3 \mathrm{C} 1$ & chr5:142757312 & $\operatorname{cg} 25535999$ & -0.001 & 0.002 & -0.42 & 0.671 & No & No & No \\
\hline $\mathrm{NR} 3 \mathrm{C} 1$ & chr5:142784462 & $\operatorname{cg} 16335926$ & 0.000 & 0.001 & 0.32 & 0.747 & No & No & No \\
\hline $\mathrm{NR} 3 \mathrm{C} 1$ & chr5:142783621 & $\operatorname{cg} 15910486$ & 0.000 & 0.001 & 0.32 & 0.751 & No & No & No \\
\hline $\mathrm{NR} 3 \mathrm{C} 1$ & chr5:142692961 & $\operatorname{cg} 19457823$ & 0.002 & 0.005 & 0.32 & 0.752 & No & No & No \\
\hline $\mathrm{NR} 3 \mathrm{C} 1$ & chr5:142781723 & $\operatorname{cg} 27122725$ & 0.002 & 0.006 & 0.30 & 0.761 & No & No & No \\
\hline $\mathrm{NR} 3 \mathrm{C} 1$ & chr5:142783383 & $\operatorname{cg} 11152298$ & 0.000 & 0.002 & -0.30 & 0.761 & No & No & No \\
\hline $\mathrm{NR} 3 \mathrm{C} 1$ & chr5:142784522 & $\operatorname{cg} 10847032$ & 0.000 & 0.001 & -0.27 & 0.784 & No & No & No \\
\hline $\mathrm{NR} 3 \mathrm{C} 1$ & chr5:142784721 & $\operatorname{cg} 21702128$ & 0.001 & 0.003 & 0.24 & 0.807 & No & No & No \\
\hline $\mathrm{NR} 3 \mathrm{C} 1$ & chr5:142783843 & $\operatorname{cg} 18068240$ & 0.000 & 0.001 & 0.23 & 0.815 & No & No & No \\
\hline NR3C1 & chr5:142779552 & $\operatorname{cg} 06613263$ & 0.000 & 0.003 & 0.18 & 0.857 & No & No & No \\
\hline
\end{tabular}




\begin{tabular}{|c|c|c|c|c|c|c|c|c|c|}
\hline NR3C1 & chr5:142783379 & $\operatorname{cg} 00629244$ & 0.000 & 0.000 & -0.09 & 0.930 & No & No & No \\
\hline NR3C1 & chr5:142783607 & $\operatorname{cg} 04111177$ & 0.000 & 0.002 & -0.06 & 0.955 & No & No & No \\
\hline NR3C1 & chr5:142757011 & $\operatorname{cg} 16586394$ & 0.000 & 0.002 & 0.00 & 0.997 & No & No & No \\
\hline NR3C1 & chr5:142782791 & $\operatorname{cg} 20753294$ & -0.001 & 0.003 & -0.27 & 0.791 & No & No & No \\
\hline $\mathrm{NR} 3 \mathrm{C} 1$ & chr5:142782827 & $\operatorname{cg} 18146873$ & 0.000 & 0.002 & 0.20 & 0.840 & No & No & No \\
\hline OXTR & chr3:8810077 & $\operatorname{cg} 12695586$ & 0.004 & 0.003 & 1.42 & 0.158 & No & No & No \\
\hline OXTR & chr3:8810549 & $\operatorname{cg} 03987506$ & -0.006 & 0.004 & -1.38 & 0.168 & No & No & No \\
\hline OXTR & chr3:8810139 & $\operatorname{cg} 19619174$ & -0.002 & 0.002 & -1.22 & 0.223 & No & No & No \\
\hline OXTR & chr3:8811543 & $\operatorname{cg} 00247334$ & 0.004 & 0.004 & 0.99 & 0.326 & No & No & No \\
\hline OXTR & chr3:8811601 & $\operatorname{cg} 17036624$ & 0.006 & 0.007 & 0.93 & 0.356 & No & No & No \\
\hline OXTR & $\operatorname{chr} 3: 8811437$ & $\operatorname{cg} 25140571$ & 0.004 & 0.006 & 0.71 & 0.479 & No & No & No \\
\hline OXTR & chr3:8808259 & $\operatorname{cg} 00385883$ & -0.001 & 0.002 & -0.70 & 0.483 & No & No & No \\
\hline OXTR & $\operatorname{chr} 3: 8811758$ & $\operatorname{cg} 14483142$ & 0.003 & 0.005 & 0.69 & 0.494 & No & No & No \\
\hline OXTR & chr3:8809306 & $\operatorname{cg} 15317815$ & 0.004 & 0.007 & 0.53 & 0.600 & No & No & No \\
\hline OXTR & $\operatorname{chr} 3: 8806317$ & $\operatorname{cg} 11589699$ & 0.001 & 0.002 & 0.52 & 0.603 & No & No & No \\
\hline OXTR & chr3:8809715 & $\operatorname{cg} 27501759$ & 0.001 & 0.001 & 0.43 & 0.669 & No & No & No \\
\hline OXTR & $\operatorname{chr} 3: 8809501$ & $\operatorname{cg} 04523291$ & -0.002 & 0.006 & -0.36 & 0.722 & No & No & No \\
\hline OXTR & $\operatorname{chr} 3: 8810592$ & $\operatorname{cg} 00078085$ & -0.001 & 0.005 & -0.11 & 0.911 & No & No & No \\
\hline OXTR & chr3:8809536 & $\operatorname{cg} 02192228$ & 0.000 & 0.005 & -0.01 & 0.990 & No & No & No \\
\hline OXTR & $\operatorname{chr} 3: 8811279$ & $\operatorname{cg} 23391006$ & 0.001 & 0.002 & 0.77 & 0.445 & No & No & No \\
\hline OXTR & chr3:8811004 & $\operatorname{cg} 17285225$ & 0.000 & 0.001 & -0.31 & 0.753 & No & No & No \\
\hline OXTR & $\operatorname{chr} 3: 8811092$ & $\operatorname{cg} 09353063$ & 0.000 & 0.002 & -0.23 & 0.822 & No & No & No \\
\hline OXTR & chr3:8810980 & $\operatorname{cg} 08535600$ & 0.000 & 0.003 & 0.15 & 0.883 & No & No & No \\
\hline SLC6A4 & chr17:28564094 & $\operatorname{cg} 06841846$ & 0.005 & 0.002 & 2.75 & 0.006 & No & No & Yes \\
\hline SLC6A4 & chr17:28563089 & $\operatorname{cg} 26741280$ & -0.004 & 0.002 & -1.97 & 0.051 & No & No & No \\
\hline SLC6A4 & chr17:28563119 & $\operatorname{cg} 27569822$ & 0.002 & 0.001 & 1.90 & 0.059 & No & No & No \\
\hline SLC6A4 & $\operatorname{chr} 17: 28524160$ & cg20592995 & -0.003 & 0.002 & -1.27 & 0.207 & No & No & No \\
\hline SLC6A4 & chr17:28559497 & $\operatorname{cg} 26126367$ & -0.002 & 0.002 & -1.16 & 0.248 & No & No & No \\
\hline SLC6A4 & $\operatorname{chr} 17: 28562142$ & $\operatorname{cg} 05951817$ & 0.003 & 0.006 & 0.58 & 0.561 & No & No & No \\
\hline SLC6A4 & chr17:28562220 & $\operatorname{cg} 22584138$ & -0.004 & 0.007 & -0.57 & 0.571 & No & No & No \\
\hline SLC6A4 & $\operatorname{chr} 17: 28548496$ & cg24984698 & -0.001 & 0.002 & -0.49 & 0.622 & No & No & No \\
\hline SLC6A4 & chr17:28562474 & $\operatorname{cg} 03363743$ & -0.002 & 0.004 & -0.44 & 0.659 & No & No & No \\
\hline SLC6A4 & $\operatorname{chr} 17: 28563054$ & $\operatorname{cg} 25725890$ & -0.001 & 0.002 & -0.43 & 0.667 & No & No & No \\
\hline SLC6A4 & $\operatorname{chr} 17: 28563300$ & $\operatorname{cg} 18584905$ & 0.001 & 0.003 & 0.31 & 0.755 & No & No & No \\
\hline SLC6A4 & chr17:28549806 & $\operatorname{cg} 01330016$ & 0.000 & 0.002 & -0.07 & 0.945 & No & No & No \\
\hline SLC6A4 & chr17:28562685 & $\operatorname{cg} 14692377$ & 0.000 & 0.002 & -0.31 & 0.757 & No & No & No \\
\hline SLC6A4 & chr17:28562813 & $\operatorname{cg} 05016953$ & 0.000 & 0.001 & -0.30 & 0.761 & $\mathrm{No}$ & $\mathrm{No}$ & No \\
\hline
\end{tabular}


Note . $\mathrm{Chr}=$ chromosome; sign = significance. Gene-wide significance was calculated as $0.05 / \mathrm{n}$ probes within the gene. The gene-wide thresholds were $<0.001$ for BDNF (74 probes), $<0.001$ for NR3C1 (40 probes), 0.003 for OXTR (18 probes), 0.004 for SLC6A4 (14 probes). 
ST5. Gene ontology in-house results with MissMethyl validation

\begin{tabular}{|c|c|c|c|c|c|c|c|}
\hline ID & Name & $\begin{array}{l}\text { nGenesinPathw } \\
\text { ay }\end{array}$ & $\begin{array}{l}\text { nTestListinPathw } \\
\text { ay }\end{array}$ & $\begin{array}{c}\text { P:GenesinTestL } \\
\text { ist }\end{array}$ & OR & P:GeneSize & $\begin{array}{c}\text { Beta:GeneSi } \\
\text { ze }\end{array}$ \\
\hline $\begin{array}{l}\text { GO:00147 } \\
01\end{array}$ & junctional sarcoplasmic reticulum membrane & 10 & 3 & $2.75 \mathrm{E}-22$ & 1.02 & 0.588 & 4.72E-06 \\
\hline $\begin{array}{l}\text { GO:00152 } \\
\quad 78\end{array}$ & calcium-release channel activity & 17 & 4 & $1.54 \mathrm{E}-20$ & 1.02 & 0.000 & 4.89E-05 \\
\hline $\begin{array}{l}\text { GO:00330 } \\
17\end{array}$ & sarcoplasmic reticulum membrane & 35 & 5 & $3.89 \mathrm{E}-17$ & 1.03 & 0.804 & 4.05E-06 \\
\hline $\begin{array}{l}\text { GO: } 00033 \\
09\end{array}$ & type B pancreatic cell differentiation & 16 & 3 & $5.23 \mathrm{E}-14$ & 1.02 & 0.483 & $7.75 \mathrm{E}-06$ \\
\hline $\begin{array}{l}\text { GO: } 00050 \\
24\end{array}$ & $\begin{array}{l}\text { transforming growth factor beta-activated } \\
\text { receptor activity }\end{array}$ & 17 & 3 & $8.86 \mathrm{E}-14$ & 1.02 & 0.633 & $-5.44 \mathrm{E}-06$ \\
\hline $\begin{array}{l}\text { GO:00046 } \\
\quad 75\end{array}$ & $\begin{array}{l}\text { transmembrane receptor protein } \\
\text { serine/threonine kinase activity }\end{array}$ & 17 & 3 & $8.86 \mathrm{E}-14$ & 1.02 & 0.633 & $-5.44 \mathrm{E}-06$ \\
\hline $\begin{array}{l}\text { GO:00148 } \\
\quad 97\end{array}$ & striated muscle hypertrophy & 17 & 3 & $5.81 \mathrm{E}-12$ & 1.02 & 0.001 & $3.84 \mathrm{E}-05$ \\
\hline $\begin{array}{l}\text { GO: } 00033 \\
00\end{array}$ & cardiac muscle hypertrophy & 17 & 3 & $5.81 \mathrm{E}-12$ & 1.02 & 0.001 & $3.84 \mathrm{E}-05$ \\
\hline $\begin{array}{l}\text { GO:00463 } \\
\quad 32\end{array}$ & SMAD binding & 61 & 6 & $1.85 \mathrm{E}-11$ & 1.03 & 0.000 & $1.11 \mathrm{E}-04$ \\
\hline $\begin{array}{l}\text { GO:00603 } \\
16\end{array}$ & $\begin{array}{l}\text { positive regulation of ryanodine-sensitive } \\
\text { calcium-release channel activity }\end{array}$ & 10 & 2 & $3.11 \mathrm{E}-11$ & 1.01 & 0.282 & $-9.39 \mathrm{E}-06$ \\
\hline $\begin{array}{l}\text { GO:00425 } \\
\quad 54\end{array}$ & superoxide anion generation & 11 & 2 & $1.81 \mathrm{E}-10$ & 1.01 & 0.148 & $-1.33 \mathrm{E}-05$ \\
\hline $\begin{array}{l}\text { GO:00328 } \\
\quad 63\end{array}$ & activation of Rac GTPase activity & 10 & 2 & $1.87 \mathrm{E}-10$ & 1.01 & 0.461 & $6.43 \mathrm{E}-06$ \\
\hline $\begin{array}{l}\text { GO:00181 } \\
07\end{array}$ & peptidyl-threonine phosphorylation & 38 & 4 & $2.75 \mathrm{E}-10$ & 1.03 & 0.647 & 7.78E-06 \\
\hline $\begin{array}{l}\text { GO:00509 } \\
19\end{array}$ & negative chemotaxis & 10 & 2 & $1.05 \mathrm{E}-09$ & 1.01 & 0.010 & 2.24E-05 \\
\hline $\begin{array}{l}\text { GO:00071 } \\
\quad 64\end{array}$ & establishment of tissue polarity & 12 & 2 & $6.27 \mathrm{E}-09$ & 1.01 & 0.625 & 4.68E-06 \\
\hline $\begin{array}{l}\text { GO:00017 } \\
36\end{array}$ & establishment of planar polarity & 12 & 2 & $6.27 \mathrm{E}-09$ & 1.01 & 0.625 & $4.68 \mathrm{E}-06$ \\
\hline $\begin{array}{l}\text { GO:00328 } \\
\quad 55\end{array}$ & positive regulation of Rac GTPase activity & 28 & 3 & $1.84 \mathrm{E}-08$ & 1.02 & 0.904 & $-1.76 \mathrm{E}-06$ \\
\hline GO:00000 & protein targeting to Golgi & 15 & 2 & 2.09E-08 & 1.01 & 0.009 & $-2.81 \mathrm{E}-05$ \\
\hline $\begin{array}{l}\text { GO: } 00190 \\
\quad 68\end{array}$ & virion assembly & 14 & 2 & 2.33E-08 & 1.01 & 0.245 & $-1.20 \mathrm{E}-05$ \\
\hline
\end{tabular}




\begin{tabular}{|c|c|c|c|c|c|c|c|}
\hline $\begin{array}{l}\text { GO: } 00335 \\
98\end{array}$ & mammary gland epithelial cell proliferation & 13 & 2 & 2.97E-08 & 1.01 & 0.536 & $6.16 \mathrm{E}-06$ \\
\hline $\begin{array}{l}\text { GO:00901 } \\
\quad 29\end{array}$ & positive regulation of synapse maturation & 12 & 2 & $4.10 \mathrm{E}-08$ & 1.01 & 0.007 & $2.56 \mathrm{E}-05$ \\
\hline $\begin{array}{l}\text { GO:00901 } \\
\quad 78\end{array}$ & $\begin{array}{l}\text { regulation of establishment of planar polarity } \\
\text { involved in neural tube closure }\end{array}$ & 13 & 2 & 4.67E-08 & 1.01 & 0.248 & $1.15 \mathrm{E}-05$ \\
\hline $\begin{array}{l}\text { GO:00901 } \\
79\end{array}$ & $\begin{array}{l}\text { planar cell polarity pathway involved in neural } \\
\text { tube closure }\end{array}$ & 13 & 2 & 4.67E-08 & 1.01 & 0.248 & $1.15 \mathrm{E}-05$ \\
\hline $\begin{array}{l}\text { GO:00328 } \\
56\end{array}$ & activation of Ras GTPase activity & 30 & 3 & $6.25 \mathrm{E}-08$ & 1.02 & 0.902 & $-1.86 \mathrm{E}-06$ \\
\hline $\begin{array}{l}\text { GO:00488 } \\
\quad 41\end{array}$ & $\begin{array}{l}\text { regulation of axon extension involved in axon } \\
\text { guidance }\end{array}$ & 13 & 2 & $6.90 \mathrm{E}-08$ & 1.01 & 0.103 & $1.62 \mathrm{E}-05$ \\
\hline $\begin{array}{l}\text { GO:00604 } \\
\quad 87\end{array}$ & lung epithelial cell differentiation & 27 & 3 & $7.49 \mathrm{E}-08$ & 1.02 & 0.019 & $3.36 \mathrm{E}-05$ \\
\hline $\begin{array}{l}\text { GO: } 00850 \\
29\end{array}$ & extracellular matrix assembly & 11 & 2 & $9.57 \mathrm{E}-08$ & 1.01 & 0.000 & $5.14 \mathrm{E}-05$ \\
\hline $\begin{array}{l}\text { GO: } 00020 \\
\quad 68\end{array}$ & glandular epithelial cell development & 14 & 2 & $1.31 \mathrm{E}-07$ & 1.01 & 0.355 & $9.55 \mathrm{E}-06$ \\
\hline $\begin{array}{l}\text { GO:00217 } \\
\quad 81\end{array}$ & glial cell fate commitment & 15 & 2 & $4.79 \mathrm{E}-07$ & 1.01 & 0.222 & $1.31 \mathrm{E}-05$ \\
\hline $\begin{array}{l}\text { GO:00485 } \\
\quad 96\end{array}$ & embryonic camera-type eye morphogenesis & 28 & 3 & $5.13 \mathrm{E}-07$ & 1.02 & 0.000 & $5.83 \mathrm{E}-05$ \\
\hline $\begin{array}{l}\text { GO:00860 } \\
19\end{array}$ & $\begin{array}{c}\text { cell-cell signaling involved in cardiac } \\
\text { conduction }\end{array}$ & 14 & 2 & $5.54 \mathrm{E}-07$ & 1.01 & 0.006 & $2.86 \mathrm{E}-05$ \\
\hline $\begin{array}{l}\text { GO: } 00320 \\
08\end{array}$ & positive regulation of TOR signaling & 14 & 2 & $7.75 \mathrm{E}-07$ & 1.01 & 0.001 & $3.32 \mathrm{E}-05$ \\
\hline $\begin{array}{l}\text { GO:00001 } \\
18\end{array}$ & histone deacetylase complex & 47 & 4 & $7.75 \mathrm{E}-07$ & 1.02 & 0.000 & $8.98 \mathrm{E}-05$ \\
\hline $\begin{array}{l}\text { GO: } 00323 \\
20\end{array}$ & positive regulation of Ras GTPase activity & 110 & 6 & $2.69 \mathrm{E}-06$ & 1.03 & 0.001 & $9.92 \mathrm{E}-05$ \\
\hline $\begin{array}{l}\text { GO:00071 } \\
\quad 78\end{array}$ & $\begin{array}{l}\text { transmembrane receptor protein } \\
\text { serine/threonine kinase signaling pathway }\end{array}$ & 183 & 8 & $2.81 \mathrm{E}-06$ & 1.04 & 0.002 & $1.13 \mathrm{E}-04$ \\
\hline $\begin{array}{l}\text { GO: } 00512 \\
70\end{array}$ & regulation of cellular component movement & 537 & 16 & $3.19 \mathrm{E}-06$ & 1.07 & 0.000 & $2.86 \mathrm{E}-04$ \\
\hline $\begin{array}{l}\text { GO:00162 } \\
09\end{array}$ & antioxidant activity & 67 & 4 & $3.42 \mathrm{E}-06$ & 1.02 & 0.494 & $-1.54 \mathrm{E}-05$ \\
\hline $\begin{array}{l}\text { GO:00321 } \\
\quad 48\end{array}$ & activation of protein kinase $B$ activity & 17 & 2 & $6.37 \mathrm{E}-06$ & 1.01 & 0.015 & $2.77 \mathrm{E}-05$ \\
\hline $\begin{array}{l}\text { GO:00459 } \\
\quad 95\end{array}$ & regulation of embryonic development & 89 & 5 & $9.58 \mathrm{E}-06$ & 1.03 & 0.003 & 7.64E-05 \\
\hline $\begin{array}{l}\text { GO:00020 } \\
\quad 88\end{array}$ & lens development in camera-type eye & 63 & 4 & $1.21 \mathrm{E}-05$ & 1.02 & 0.018 & $5.17 \mathrm{E}-05$ \\
\hline
\end{tabular}




\begin{tabular}{|c|c|c|c|c|c|c|c|}
\hline $\begin{array}{l}\text { GO:00606 } \\
03\end{array}$ & mammary gland duct morphogenesis & 37 & 3 & $1.38 \mathrm{E}-05$ & 1.02 & 0.003 & 4.93E-05 \\
\hline $\begin{array}{l}\text { GO:00063 } \\
52\end{array}$ & DNA-templated transcription & 209 & 8 & $2.06 \mathrm{E}-05$ & 1.04 & 0.007 & $1.08 \mathrm{E}-04$ \\
\hline $\begin{array}{l}\text { GO:00016 } \\
54\end{array}$ & eye development & 292 & 10 & $2.19 \mathrm{E}-05$ & 1.05 & 0.000 & $1.63 \mathrm{E}-04$ \\
\hline $\begin{array}{l}\text { GO:00026 } \\
90\end{array}$ & positive regulation of leukocyte chemotaxis & 54 & 3 & $3.13 \mathrm{E}-05$ & 1.02 & 0.012 & $-5.10 \mathrm{E}-05$ \\
\hline $\begin{array}{l}\text { GO: } 00350 \\
88\end{array}$ & $\begin{array}{l}\text { establishment or maintenance of apical/basal } \\
\text { cell polarity }\end{array}$ & 21 & 2 & $3.26 \mathrm{E}-05$ & 1.01 & 0.230 & $1.52 \mathrm{E}-05$ \\
\hline $\begin{array}{l}\text { GO: } 00612 \\
45\end{array}$ & $\begin{array}{l}\text { establishment or maintenance of bipolar cell } \\
\text { polarity }\end{array}$ & 21 & 2 & $3.26 \mathrm{E}-05$ & 1.01 & 0.230 & $1.52 \mathrm{E}-05$ \\
\hline $\begin{array}{l}\text { GO:00457 } \\
78\end{array}$ & positive regulation of ossification & 44 & 3 & 4.23E-05 & 1.02 & 0.141 & $2.69 \mathrm{E}-05$ \\
\hline $\begin{array}{l}\text { GO:00509 } \\
18\end{array}$ & positive chemotaxis & 24 & 2 & $5.36 \mathrm{E}-05$ & 1.01 & 0.866 & $-2.29 \mathrm{E}-06$ \\
\hline $\begin{array}{l}\text { GO: } 00483 \\
65\end{array}$ & Rac GTPase binding & 22 & 2 & $5.77 \mathrm{E}-05$ & 1.01 & 0.178 & $1.75 \mathrm{E}-05$ \\
\hline $\begin{array}{l}\text { GO:00322 } \\
\quad 92\end{array}$ & peripheral nervous system axon ensheathment & 21 & 2 & $7.00 \mathrm{E}-05$ & 1.01 & 0.015 & $3.08 \mathrm{E}-05$ \\
\hline $\begin{array}{l}\text { GO: } 00220 \\
11\end{array}$ & myelination in peripheral nervous system & 21 & 2 & $7.00 \mathrm{E}-05$ & 1.01 & 0.015 & 3.08E-05 \\
\hline $\begin{array}{l}\text { GO: } 20000 \\
26\end{array}$ & $\begin{array}{c}\text { regulation of multicellular organismal } \\
\text { development }\end{array}$ & 1236 & 27 & 8.43E-05 & 1.09 & 0.000 & 7.68E-04 \\
\hline $\begin{array}{l}\text { GO:00011 } \\
05\end{array}$ & $\begin{array}{l}\text { RNA polymerase II transcription coactivator } \\
\text { activity }\end{array}$ & 23 & 2 & $1.14 \mathrm{E}-04$ & 1.01 & 0.079 & $2.33 \mathrm{E}-05$ \\
\hline $\begin{array}{l}\text { GO:00017 } \\
09\end{array}$ & cell fate determination & 43 & 3 & $1.33 \mathrm{E}-04$ & 1.02 & 0.000 & $6.83 \mathrm{E}-05$ \\
\hline $\begin{array}{l}\text { GO:00170 } \\
16\end{array}$ & Ras GTPase binding & 151 & 6 & $1.33 \mathrm{E}-04$ & 1.03 & 0.014 & $8.29 \mathrm{E}-05$ \\
\hline $\begin{array}{l}\text { GO: } 20012 \\
\quad 35\end{array}$ & $\begin{array}{l}\text { positive regulation of apoptotic signaling } \\
\text { pathway }\end{array}$ & 120 & 5 & $1.57 \mathrm{E}-04$ & 1.03 & 0.194 & $3.92 \mathrm{E}-05$ \\
\hline $\begin{array}{l}\text { GO:00160 } \\
55\end{array}$ & Wnt signaling pathway & 227 & 8 & $1.60 \mathrm{E}-04$ & 1.04 & 0.000 & $1.70 \mathrm{E}-04$ \\
\hline $\begin{array}{l}\text { GO:00069 } \\
35\end{array}$ & chemotaxis & 560 & 15 & $1.61 \mathrm{E}-04$ & 1.06 & 0.000 & $4.05 \mathrm{E}-04$ \\
\hline $\begin{array}{l}\text { GO:00423 } \\
30\end{array}$ & taxis & 560 & 15 & $1.61 \mathrm{E}-04$ & 1.06 & 0.000 & 4.05E-04 \\
\hline $\begin{array}{l}\text { GO:00018 } \\
43\end{array}$ & neural tube closure & 74 & 4 & $2.71 \mathrm{E}-04$ & 1.02 & 0.000 & $1.02 \mathrm{E}-04$ \\
\hline $\begin{array}{l}\text { GO:00019 } \\
36\end{array}$ & regulation of endothelial cell proliferation & 85 & 4 & $3.13 \mathrm{E}-04$ & 1.02 & 0.047 & $5.05 \mathrm{E}-05$ \\
\hline
\end{tabular}




\begin{tabular}{|c|c|c|c|c|c|c|c|}
\hline $\begin{array}{l}\text { GO:00718 } \\
\quad 89\end{array}$ & $14-3-3$ protein binding & 18 & 2 & $3.65 \mathrm{E}-04$ & 1.01 & 0.000 & 9.33E-05 \\
\hline $\begin{array}{l}\text { GO: } 20001 \\
\quad 45\end{array}$ & regulation of cell motility & 477 & 12 & $5.45 \mathrm{E}-04$ & 1.05 & 0.000 & $2.12 \mathrm{E}-04$ \\
\hline $\begin{array}{l}\text { GO:00085 } \\
\quad 44\end{array}$ & epidermis development & 241 & 7 & $5.66 \mathrm{E}-04$ & 1.03 & 0.646 & $1.96 \mathrm{E}-05$ \\
\hline $\begin{array}{l}\text { GO:00712 } \\
77\end{array}$ & cellular response to calcium ion & 33 & 2 & $6.22 \mathrm{E}-04$ & 1.01 & 0.539 & $-9.74 \mathrm{E}-06$ \\
\hline $\begin{array}{l}\text { GO: } 00427 \\
53\end{array}$ & positive regulation of circadian rhythm & 10 & 1 & $6.61 \mathrm{E}-04$ & 1.01 & 0.254 & $-9.98 \mathrm{E}-06$ \\
\hline $\begin{array}{l}\text { GO: } 00305 \\
46\end{array}$ & receptor activator activity & 28 & 2 & $7.25 \mathrm{E}-04$ & 1.01 & 0.042 & $2.98 \mathrm{E}-05$ \\
\hline $\begin{array}{l}\text { GO: } 00450 \\
\quad 80\end{array}$ & $\begin{array}{c}\text { positive regulation of chemokine biosynthetic } \\
\text { process }\end{array}$ & 10 & 1 & 7.30E-04 & 1.01 & 0.341 & $-8.32 \mathrm{E}-06$ \\
\hline $\begin{array}{l}\text { GO: } 00400 \\
20\end{array}$ & regulation of meiosis & 30 & 2 & 7.31E-04 & 1.01 & 0.297 & $1.58 \mathrm{E}-05$ \\
\hline $\begin{array}{l}\text { GO:00168 } \\
88\end{array}$ & endodeoxyribonuclease activity & 10 & 1 & 7.64E-04 & 1.01 & 0.388 & $-7.55 \mathrm{E}-06$ \\
\hline $\begin{array}{l}\text { GO: } 20003 \\
79\end{array}$ & $\begin{array}{l}\text { positive regulation of reactive oxygen species } \\
\text { metabolic process }\end{array}$ & 32 & 2 & 7.72E-04 & 1.01 & 0.819 & $3.58 \mathrm{E}-06$ \\
\hline $\begin{array}{l}\text { GO:00400 } \\
36\end{array}$ & $\begin{array}{c}\text { regulation of fibroblast growth factor receptor } \\
\text { signaling pathway }\end{array}$ & 27 & 2 & 7.79E-04 & 1.01 & 0.007 & $3.90 \mathrm{E}-05$ \\
\hline $\begin{array}{l}\text { GO:00164 } \\
\quad 93\end{array}$ & C-C chemokine receptor activity & 11 & 1 & $7.98 \mathrm{E}-04$ & 1.01 & 0.057 & $-1.74 \mathrm{E}-05$ \\
\hline $\begin{array}{l}\text { GO:00066 } \\
23\end{array}$ & protein targeting to vacuole & 10 & 1 & 8.69E-04 & 1.01 & 0.538 & $-5.38 \mathrm{E}-06$ \\
\hline $\begin{array}{l}\text { GO:00726 } \\
\quad 66\end{array}$ & establishment of protein localization to vacuole & 10 & 1 & 8.69E-04 & 1.01 & 0.538 & $-5.38 \mathrm{E}-06$ \\
\hline $\begin{array}{l}\text { GO:00066 } \\
22\end{array}$ & protein targeting to lysosome & 10 & 1 & $8.69 \mathrm{E}-04$ & 1.01 & 0.538 & $-5.38 \mathrm{E}-06$ \\
\hline $\begin{array}{l}\text { GO:00009 } \\
\quad 79\end{array}$ & $\begin{array}{l}\text { RNA polymerase II core promoter sequence- } \\
\text { specific DNA binding }\end{array}$ & 29 & 2 & $9.05 \mathrm{E}-04$ & 1.01 & 0.051 & $2.90 \mathrm{E}-05$ \\
\hline $\begin{array}{l}\text { GO:00048 } \\
\quad 87\end{array}$ & thyroid hormone receptor activity & 10 & 1 & $9.44 \mathrm{E}-04$ & 1.01 & 0.649 & $-3.98 \mathrm{E}-06$ \\
\hline $\begin{array}{l}\text { GO:00336 } \\
\quad 92\end{array}$ & cellular polysaccharide biosynthetic process & 35 & 2 & $9.84 \mathrm{E}-04$ & 1.01 & 0.590 & $-8.82 \mathrm{E}-06$ \\
\hline $\begin{array}{l}\text { GO:00465 } \\
\quad 45\end{array}$ & $\begin{array}{c}\text { development of primary female sexual } \\
\text { characteristics }\end{array}$ & 104 & 4 & $9.94 \mathrm{E}-04$ & 1.02 & 0.514 & $1.84 \mathrm{E}-05$ \\
\hline $\begin{array}{l}\text { GO:00329 } \\
28\end{array}$ & regulation of superoxide anion generation & 10 & 1 & $9.94 \mathrm{E}-04$ & 1.01 & 0.724 & $-3.09 \mathrm{E}-06$ \\
\hline $\begin{array}{l}\text { GO:00339 } \\
\quad 62\end{array}$ & cytoplasmic mRNA processing body assembly & 10 & 1 & $1.05 \mathrm{E}-03$ & 1.01 & 0.802 & $-2.19 \mathrm{E}-06$ \\
\hline
\end{tabular}




\begin{tabular}{|c|c|c|c|c|c|c|c|}
\hline $\begin{array}{l}\text { GO:00109 } \\
\quad 35\end{array}$ & regulation of macrophage cytokine production & 10 & 1 & $1.06 \mathrm{E}-03$ & 1.01 & 0.824 & $-1.94 \mathrm{E}-06$ \\
\hline $\begin{array}{l}\text { GO:00442 } \\
\quad 92\end{array}$ & dendrite terminus & 10 & 1 & $1.17 \mathrm{E}-03$ & 1.01 & 0.974 & $-2.81 \mathrm{E}-07$ \\
\hline $\begin{array}{l}\text { GO: } 00518 \\
65\end{array}$ & protein autoubiquitination & 34 & 2 & $1.30 \mathrm{E}-03$ & 1.01 & 0.679 & $6.67 \mathrm{E}-06$ \\
\hline $\begin{array}{l}\text { GO:00432 } \\
56\end{array}$ & laminin complex & 10 & 1 & $1.31 \mathrm{E}-03$ & 1.01 & 0.840 & $1.76 \mathrm{E}-06$ \\
\hline $\begin{array}{l}\text { GO: } 00452 \\
\quad 92\end{array}$ & mRNA cis splicing & 11 & 1 & 1.37E-03 & 1.01 & 0.399 & $-7.73 \mathrm{E}-06$ \\
\hline $\begin{array}{l}\text { GO:00606 } \\
38\end{array}$ & mesenchymal-epithelial cell signaling & 10 & 1 & $1.42 \mathrm{E}-03$ & 1.01 & 0.717 & $3.16 \mathrm{E}-06$ \\
\hline $\begin{array}{l}\text { GO:00900 } \\
09\end{array}$ & primitive streak formation & 10 & 1 & $1.57 \mathrm{E}-03$ & 1.01 & 0.571 & 4.95E-06 \\
\hline $\begin{array}{l}\text { GO:00083 } \\
54\end{array}$ & germ cell migration & 11 & 1 & $1.62 \mathrm{E}-03$ & 1.01 & 0.621 & $-4.54 \mathrm{E}-06$ \\
\hline $\begin{array}{l}\text { GO:00702 } \\
\quad 34\end{array}$ & positive regulation of $\mathrm{T}$ cell apoptotic process & 11 & 1 & $1.77 \mathrm{E}-03$ & 1.01 & 0.753 & $-2.88 \mathrm{E}-06$ \\
\hline $\begin{array}{l}\text { GO:00005 } \\
\quad 78\end{array}$ & embryonic axis specification & 33 & 2 & $1.82 \mathrm{E}-03$ & 1.01 & 0.131 & 2.39E-05 \\
\hline $\begin{array}{l}\text { GO:00095 } \\
\quad 66\end{array}$ & fertilization & 132 & 4 & $1.84 \mathrm{E}-03$ & 1.02 & 0.048 & $-6.25 \mathrm{E}-05$ \\
\hline $\begin{array}{c}\text { GO: } 20002 \\
51\end{array}$ & $\begin{array}{l}\text { positive regulation of actin cytoskeleton } \\
\text { reorganization }\end{array}$ & 11 & 1 & $1.87 \mathrm{E}-03$ & 1.01 & 0.839 & $-1.86 \mathrm{E}-06$ \\
\hline $\begin{array}{l}\text { GO:00053 } \\
37\end{array}$ & nucleoside transmembrane transporter activity & 12 & 1 & $1.89 \mathrm{E}-03$ & 1.01 & 0.247 & $-1.11 \mathrm{E}-05$ \\
\hline $\begin{array}{l}\text { GO:00336 } \\
\quad 34\end{array}$ & $\begin{array}{l}\text { positive regulation of cell-cell adhesion } \\
\text { mediated by integrin }\end{array}$ & 10 & 1 & $1.91 \mathrm{E}-03$ & 1.01 & 0.337 & $8.40 \mathrm{E}-06$ \\
\hline $\begin{array}{l}\text { GO:00062 } \\
\quad 89\end{array}$ & nucleotide-excision repair & 75 & 3 & $1.91 \mathrm{E}-03$ & 1.02 & 0.770 & $-6.98 \mathrm{E}-06$ \\
\hline $\begin{array}{l}\text { GO:00106 } \\
40\end{array}$ & $\begin{array}{l}\text { regulation of platelet-derived growth factor } \\
\text { receptor signaling pathway }\end{array}$ & 11 & 1 & $2.02 \mathrm{E}-03$ & 1.01 & 0.971 & $-3.29 \mathrm{E}-07$ \\
\hline $\begin{array}{l}\text { GO:00068 } \\
\quad 95\end{array}$ & Golgi to endosome transport & 12 & 1 & $2.05 \mathrm{E}-03$ & 1.01 & 0.318 & $-9.56 \mathrm{E}-06$ \\
\hline $\begin{array}{l}\text { GO:00971 } \\
\quad 86\end{array}$ & amelogenesis & 11 & 1 & $2.28 \mathrm{E}-03$ & 1.01 & 0.830 & $1.97 \mathrm{E}-06$ \\
\hline $\begin{array}{l}\text { GO:00190 } \\
\quad 82\end{array}$ & viral protein processing & 12 & 1 & $2.31 \mathrm{E}-03$ & 1.01 & 0.456 & $-7.14 \mathrm{E}-06$ \\
\hline $\begin{array}{l}\text { GO:00340 } \\
\quad 45\end{array}$ & pre-autophagosomal structure membrane & 11 & 1 & $2.36 \mathrm{E}-03$ & 1.01 & 0.776 & $2.61 \mathrm{E}-06$ \\
\hline $\begin{array}{l}\text { GO:00019 } \\
21\end{array}$ & positive regulation of receptor recycling & 11 & 1 & $2.52 \mathrm{E}-03$ & 1.01 & 0.672 & $3.88 \mathrm{E}-06$ \\
\hline
\end{tabular}




\begin{tabular}{|c|c|c|c|c|c|c|c|}
\hline $\begin{array}{l}\text { GO: } 00220 \\
38\end{array}$ & corpus callosum development & 10 & 1 & $2.53 \mathrm{E}-03$ & 1.01 & 0.119 & $1.36 \mathrm{E}-05$ \\
\hline $\begin{array}{l}\text { GO:00508 } \\
57\end{array}$ & $\begin{array}{c}\text { positive regulation of antigen receptor-mediated } \\
\text { signaling pathway }\end{array}$ & 12 & 1 & $2.62 \mathrm{E}-03$ & 1.01 & 0.632 & $-4.59 \mathrm{E}-06$ \\
\hline $\begin{array}{l}\text { GO:00001 } \\
09\end{array}$ & nucleotide-excision repair complex & 12 & 1 & $2.65 \mathrm{E}-03$ & 1.01 & 0.651 & $-4.33 \mathrm{E}-06$ \\
\hline $\begin{array}{l}\text { GO:00340 } \\
\quad 62\end{array}$ & RNA polymerase activity & 41 & 2 & 2.73E-03 & 1.01 & 0.586 & $-9.62 \mathrm{E}-06$ \\
\hline $\begin{array}{l}\text { GO:00038 } \\
99\end{array}$ & DNA-directed RNA polymerase activity & 41 & 2 & $2.73 \mathrm{E}-03$ & 1.01 & 0.586 & $-9.62 \mathrm{E}-06$ \\
\hline $\begin{array}{l}\text { GO:00108 } \\
75\end{array}$ & positive regulation of cholesterol efflux & 11 & 1 & $2.79 \mathrm{E}-03$ & 1.01 & 0.518 & 5.92E-06 \\
\hline $\begin{array}{l}\text { GO: } 00328 \\
39\end{array}$ & dendrite cytoplasm & 12 & 1 & $2.85 \mathrm{E}-03$ & 1.01 & 0.770 & $-2.80 \mathrm{E}-06$ \\
\hline $\begin{array}{l}\text { GO:00432 } \\
\quad 52\end{array}$ & sodium-independent organic anion transport & 13 & 1 & $2.90 \mathrm{E}-03$ & 1.01 & 0.258 & $-1.13 \mathrm{E}-05$ \\
\hline $\begin{array}{l}\text { GO:00009 } \\
\quad 93\end{array}$ & RNA polymerase II core binding & 11 & 1 & $2.92 \mathrm{E}-03$ & 1.01 & 0.457 & $6.82 \mathrm{E}-06$ \\
\hline $\begin{array}{l}\text { GO:00052 } \\
\quad 47\end{array}$ & voltage-gated chloride channel activity & 12 & 1 & $3.23 \mathrm{E}-03$ & 1.01 & 0.979 & $-2.50 \mathrm{E}-07$ \\
\hline $\begin{array}{l}\text { GO:00309 } \\
71\end{array}$ & receptor tyrosine kinase binding & 38 & 2 & $3.51 \mathrm{E}-03$ & 1.01 & 0.320 & $1.69 \mathrm{E}-05$ \\
\hline $\begin{array}{l}\text { GO:00459 } \\
\quad 86\end{array}$ & $\begin{array}{l}\text { negative regulation of smooth muscle } \\
\text { contraction }\end{array}$ & 12 & 1 & $3.58 \mathrm{E}-03$ & 1.01 & 0.841 & $1.92 \mathrm{E}-06$ \\
\hline $\begin{array}{l}\text { GO:00326 } \\
77\end{array}$ & regulation of interleukin- 8 production & 45 & 2 & $3.65 \mathrm{E}-03$ & 1.01 & 0.277 & $-2.01 \mathrm{E}-05$ \\
\hline $\begin{array}{l}\text { GO:00350 } \\
\quad 98\end{array}$ & $\mathrm{ESC} / \mathrm{E}(\mathrm{Z})$ complex & 12 & 1 & $3.78 \mathrm{E}-03$ & 1.01 & 0.749 & $3.07 \mathrm{E}-06$ \\
\hline $\begin{array}{l}\text { GO:00439 } \\
\quad 81\end{array}$ & histone $\mathrm{H} 4-\mathrm{K} 5$ acetylation & 13 & 1 & $3.87 \mathrm{E}-03$ & 1.01 & 0.615 & $-5.02 \mathrm{E}-06$ \\
\hline $\begin{array}{l}\text { GO:00439 } \\
\quad 82\end{array}$ & histone $\mathrm{H} 4-\mathrm{K} 8$ acetylation & 13 & 1 & $3.87 \mathrm{E}-03$ & 1.01 & 0.615 & $-5.02 \mathrm{E}-06$ \\
\hline $\begin{array}{l}\text { GO:00082 } \\
\quad 76\end{array}$ & protein methyltransferase activity & 73 & 3 & $3.90 \mathrm{E}-03$ & 1.01 & 0.101 & $3.87 \mathrm{E}-05$ \\
\hline $\begin{array}{l}\text { GO:00017 } \\
11\end{array}$ & endodermal cell fate commitment & 13 & 1 & $4.03 \mathrm{E}-03$ & 1.01 & 0.679 & $-4.13 \mathrm{E}-06$ \\
\hline $\begin{array}{l}\text { GO:00512 } \\
05\end{array}$ & protein insertion into membrane & 12 & 1 & $4.57 \mathrm{E}-03$ & 1.01 & 0.455 & 7.15E-06 \\
\hline $\begin{array}{l}\text { GO:00308 } \\
\quad 98\end{array}$ & actin-dependent ATPase activity & 11 & 1 & $4.88 \mathrm{E}-03$ & 1.01 & 0.059 & $1.73 \mathrm{E}-05$ \\
\hline $\begin{array}{l}\text { GO:00081 } \\
\quad 71\end{array}$ & O-methyltransferase activity & 14 & 1 & $5.00 \mathrm{E}-03$ & 1.01 & 0.476 & $-7.36 \mathrm{E}-06$ \\
\hline
\end{tabular}




\begin{tabular}{|c|c|c|c|c|c|c|c|}
\hline $\begin{array}{l}\text { GO:00059 } \\
16\end{array}$ & fascia adherens & 13 & 1 & $5.08 \mathrm{E}-03$ & 1.01 & 0.912 & $1.10 \mathrm{E}-06$ \\
\hline $\begin{array}{l}\text { GO:00305 } \\
02\end{array}$ & negative regulation of bone mineralization & 15 & 1 & $5.09 \mathrm{E}-03$ & 1.01 & 0.166 & $-1.48 \mathrm{E}-05$ \\
\hline $\begin{array}{l}\text { GO:00455 } \\
\quad 40\end{array}$ & regulation of cholesterol biosynthetic process & 13 & 1 & $5.11 \mathrm{E}-03$ & 1.01 & 0.902 & $1.23 \mathrm{E}-06$ \\
\hline $\begin{array}{l}\text { GO:00107 } \\
\quad 44\end{array}$ & $\begin{array}{c}\text { positive regulation of macrophage derived foam } \\
\text { cell differentiation }\end{array}$ & 15 & 1 & $5.11 \mathrm{E}-03$ & 1.01 & 0.170 & $-1.47 \mathrm{E}-05$ \\
\hline $\begin{array}{l}\text { GO:00483 } \\
\quad 87\end{array}$ & $\begin{array}{c}\text { negative regulation of retinoic acid receptor } \\
\text { signaling pathway }\end{array}$ & 14 & 1 & $5.63 \mathrm{E}-03$ & 1.01 & 0.659 & $-4.56 \mathrm{E}-06$ \\
\hline $\begin{array}{l}\text { GO:00705 } \\
28\end{array}$ & protein kinase $\mathrm{C}$ signaling & 11 & 1 & $5.82 \mathrm{E}-03$ & 1.01 & 0.022 & $2.10 \mathrm{E}-05$ \\
\hline $\begin{array}{l}\text { GO:00190 } \\
13\end{array}$ & viral nucleocapsid & 14 & 1 & $5.90 \mathrm{E}-03$ & 1.01 & 0.742 & $-3.41 \mathrm{E}-06$ \\
\hline $\begin{array}{l}\text { GO:00450 } \\
\quad 22\end{array}$ & early endosome to late endosome transport & 14 & 1 & $6.00 \mathrm{E}-03$ & 1.01 & 0.770 & $-3.03 \mathrm{E}-06$ \\
\hline $\begin{array}{l}\text { GO:00018 } \\
\quad 91\end{array}$ & phagocytic cup & 14 & 1 & $6.91 \mathrm{E}-03$ & 1.01 & 0.968 & 4.18E-07 \\
\hline $\begin{array}{l}\text { GO:00191 } \\
\quad 98\end{array}$ & $\begin{array}{l}\text { transmembrane receptor protein phosphatase } \\
\text { activity }\end{array}$ & 20 & 2 & 7.07E-03 & 1.01 & 0.000 & $1.52 \mathrm{E}-04$ \\
\hline $\begin{array}{l}\text { GO:00050 } \\
01\end{array}$ & $\begin{array}{l}\text { transmembrane receptor protein tyrosine } \\
\text { phosphatase activity }\end{array}$ & 20 & 2 & 7.07E-03 & 1.01 & 0.000 & $1.52 \mathrm{E}-04$ \\
\hline $\begin{array}{l}\text { GO:00467 } \\
16\end{array}$ & muscle cell cellular homeostasis & 15 & 1 & 7.09E-03 & 1.01 & 0.543 & $-6.52 \mathrm{E}-06$ \\
\hline $\begin{array}{l}\text { GO:00216 } \\
84\end{array}$ & cerebellar granular layer formation & 10 & 1 & 7.27E-03 & 1.01 & 0.000 & $3.44 \mathrm{E}-05$ \\
\hline $\begin{array}{l}\text { GO:00217 } \\
07\end{array}$ & cerebellar granule cell differentiation & 10 & 1 & 7.27E-03 & 1.01 & 0.000 & $3.44 \mathrm{E}-05$ \\
\hline $\begin{array}{l}\text { GO:00065 } \\
\quad 55\end{array}$ & methionine metabolic process & 14 & 1 & $7.31 \mathrm{E}-03$ & 1.01 & 0.860 & $1.82 \mathrm{E}-06$ \\
\hline $\begin{array}{l}\text { GO:00066 } \\
\quad 07\end{array}$ & NLS-bearing protein import into nucleus & 14 & 1 & 7.47E-03 & 1.01 & 0.822 & 2.33E-06 \\
\hline $\begin{array}{l}\text { GO:00435 } \\
\quad 24\end{array}$ & negative regulation of neuron apoptotic process & 122 & 4 & $7.80 \mathrm{E}-03$ & 1.02 & 0.013 & $7.58 \mathrm{E}-05$ \\
\hline $\begin{array}{l}\text { GO:00152 } \\
\quad 99\end{array}$ & solute:hydrogen antiporter activity & 14 & 1 & $8.66 \mathrm{E}-03$ & 1.01 & 0.560 & $6.03 \mathrm{E}-06$ \\
\hline $\begin{array}{l}\text { GO:00007 } \\
26\end{array}$ & non-recombinational repair & 15 & 1 & $8.78 \mathrm{E}-03$ & 1.01 & 0.923 & $-1.03 \mathrm{E}-06$ \\
\hline $\begin{array}{l}\text { GO:00152 } \\
\quad 38\end{array}$ & drug transmembrane transporter activity & 16 & 1 & $1.11 \mathrm{E}-02$ & 1.01 & 0.867 & $-1.85 \mathrm{E}-06$ \\
\hline $\begin{array}{l}\text { GO:00309 } \\
\quad 83\end{array}$ & mismatched DNA binding & 18 & 1 & $1.21 \mathrm{E}-02$ & 1.01 & 0.275 & $-1.28 \mathrm{E}-05$ \\
\hline
\end{tabular}




\begin{tabular}{|c|c|c|c|c|c|c|c|}
\hline $\begin{array}{c}\text { GO:00324 } \\
56\end{array}$ & endocytic recycling & 15 & 1 & $1.22 \mathrm{E}-02$ & 1.01 & 0.475 & 7.64E-06 \\
\hline $\begin{array}{c}\text { GO:00003 } \\
14\end{array}$ & organellar small ribosomal subunit & 18 & 1 & $1.36 \mathrm{E}-02$ & 1.01 & 0.432 & $-9.22 \mathrm{E}-06$ \\
\hline $\begin{array}{c}\text { GO:00057 } \\
63\end{array}$ & mitochondrial small ribosomal subunit & 18 & 1 & $1.36 \mathrm{E}-02$ & 1.01 & 0.432 & $-9.22 \mathrm{E}-06$ \\
\hline
\end{tabular}

Note. $\mathrm{GO}=$ gene ontology; $\mathrm{n}=$ number; $\mathrm{OR}=$ odd ratio; $\mathrm{p}=\mathrm{p}$-value. Cells highlighted in green were pathways which were validated by the MissMethyl method $(p<0.05)$ 
ST6. mQLTs associated with the CpGs within the significant DNAm regions

\begin{tabular}{|c|c|c|c|c|}
\hline Region & Location & CpG & Gene_UCSC_Ref & SNP affecting CpG DNAm \\
\hline 1 & chr2:241458886-241460002 & $\operatorname{cg} 05371791$ & ANKMY1;ANKMY1 & NA \\
\hline 1 & chr2:241458886-241460002 & $\operatorname{cg} 06476685$ & ANKMY1;ANKMY1 & rs10165759, rs4676426 \\
\hline 1 & chr2:241458886-241460002 & $\operatorname{cg} 03743720$ & ANKMY1;ANKMY1 & rs10165759, rs4676426, rs4676425 \\
\hline 1 & chr2:241458886-241460002 & $\operatorname{cg} 24086040$ & ANKMY1;ANKMY1 & rs 3821348 \\
\hline 1 & chr2:241458886-241460002 & $\operatorname{cg} 08461339$ & ANKMY1;ANKMY1 & rs3821348, rs11285932, rs4676426 \\
\hline 1 & chr2:241458886-241460002 & $\operatorname{cg} 24539848$ & ANKMY1;ANKMY1 & rs4398270, rs13394744 \\
\hline 1 & chr2:241458886-241460002 & $\operatorname{cg} 16909733$ & ANKMY1;ANKMY1 & rs4676426, rs4676349 \\
\hline 1 & chr2:241458886-241460002 & $\operatorname{cg} 08276645$ & ANKMY1;ANKMY1 & rs 7603521, rs 4676430, rs4676426 \\
\hline 2 & chr6:30039027-30039600 & $\operatorname{cg} 00947782$ & RNF39;RNF39 & NA \\
\hline 2 & chr6:30039027-30039600 & $\operatorname{cg} 02188185$ & RNF39;RNF39 & NA \\
\hline 2 & chr6:30039027-30039600 & $\operatorname{cg} 03343571$ & RNF39;RNF39 & NA \\
\hline 2 & chr6:30039027-30039600 & $\operatorname{cg} 05563515$ & RNF39;RNF39 & NA \\
\hline 2 & chr6:30039027-30039600 & $\operatorname{cg} 06249604$ & RNF39;RNF39 & NA \\
\hline 2 & chr6:30039027-30039600 & $\operatorname{cg} 07179033$ & RNF39;RNF39 & NA \\
\hline 2 & chr6:30039027-30039600 & $\operatorname{cg} 07382347$ & RNF39;RNF39 & NA \\
\hline 2 & chr6:30039027-30039600 & $\operatorname{cg} 08491487$ & RNF39;RNF39 & NA \\
\hline 2 & chr6:30039027-30039600 & $\operatorname{cg} 09279736$ & RNF39;RNF39 & NA \\
\hline 2 & chr6:30039027-30039600 & $\operatorname{cg} 10568066$ & RNF39;RNF39 & NA \\
\hline 2 & chr6:30039027-30039600 & $\operatorname{cg} 10930308$ & RNF39;RNF39 & NA \\
\hline 2 & chr6:30039027-30039600 & $\operatorname{cg} 12633154$ & RNF39;RNF39 & NA \\
\hline 2 & chr6:30039027-30039600 & $\operatorname{cg} 13185413$ & RNF39;RNF39 & NA \\
\hline 2 & chr6:30039027-30039600 & $\operatorname{cg} 13401893$ & RNF39;RNF39 & NA \\
\hline 2 & chr6:30039027-30039600 & $\operatorname{cg} 13918754$ & RNF39;RNF39 & NA \\
\hline 2 & chr6:30039027-30039600 & $\operatorname{cg} 15877520$ & RNF39;RNF39 & NA \\
\hline 2 & chr6:30039027-30039600 & $\operatorname{cg} 16078649$ & RNF39;RNF39 & NA \\
\hline 2 & chr6:30039027-30039600 & $\operatorname{cg} 18930910$ & RNF39;RNF39 & NA \\
\hline 2 & chr6:30039027-30039600 & $\operatorname{cg} 20119745$ & RNF39;RNF39 & NA \\
\hline 2 & chr6:30039027-30039600 & $\operatorname{cg} 20249327$ & RNF39;RNF39 & NA \\
\hline 2 & chr6:30039027-30039600 & $\operatorname{cg} 23712018$ & RNF39;RNF39 & NA \\
\hline 2 & chr6:30039027-30039600 & $\operatorname{cg} 26730543$ & RNF39;RNF39 & NA \\
\hline 3 & chr6:33282879-33283184 & $\operatorname{cg} 03000593$ & ZBTB22;ТAPBP;TAPBP;TAPBP;ZBTB22 & NA \\
\hline 3 & chr6:33282879-33283184 & $\operatorname{cg} 05210804$ & ZBTB22;ТАРBP;TAPBP;TAPBP;ZBTB22 & NA \\
\hline 3 & chr6:33282879-33283184 & $\operatorname{cg} 07245868$ & ZВTB22;ТАРВP;ТAPBP;ТAPBP;ZBTB22 & NA \\
\hline 3 & chr6:33282879-33283184 & $\operatorname{cg} 07895437$ & ZBTB22;ТAPBP;TAPBP;TAPBP;ZBTB22 & NA \\
\hline 3 & chr6:33282879-33283184 & $\operatorname{cg} 08771019$ & ZBTB22;ТAPBP;TAPBP;TAPBP;ZBTB22 & NA \\
\hline
\end{tabular}


chr6:33282879-33283184 chr6:33282879-33283184 chr6:33282879-33283184 chr6:33282879-33283184 chr6:33282879-33283184 chr6:33282879-33283184 chr6:33282879-33283184 chr6:33282879-33283184 chr6:33282879-33283184 chr6:33282879-33283184 chr6:33282879-33283184 chr6:33282879-33283184 chr2:21266727-21267334 chr2:21266727-21267334 chr2:21266727-21267334 chr2:21266727-21267334 chr2:21266727-21267334 chr2:21266727-21267334 chr2:21266727-21267334 chr2:21266727-21267334 chr2:21266727-21267334 chr2:21266727-21267334 chr2:3642629-3642867 chr2:3642629-3642867 chr2:3642629-3642867 chr2:3642629-3642867 chr2:3642629-3642867 chr2:3642629-3642867 chr17:6797034-6797771 chr17:6797034-6797771 chr17:6797034-6797771 chr17:6797034-6797771 chr17:6797034-6797771 chr17:6797034-6797771 chr7:111368367-111368847 chr7:111368367-111368847 chr7:111368367-111368847 chr7:111368367-111368847 cg10134527

cg11917542 cg13027595 cg14096569 cg14309283 cg14473643 cg17055704 cg18144560 cg21330831 cg25954512 cg26646118 cg27168291 cg00673290 cg25123895 cg26112457 cg03350299 cg16723488 $\operatorname{cg} 07636176$ cg15246511 cg24309555 cg16306978 cg25071744 cg09974661 cg16430428 cg19867917 cg26615126 $\operatorname{cg} 00835279$ cg17872886 cg01758314 $\operatorname{cg} 07391831$ cg09705592 cg16893174 cg18007837 cg26334670 cg01567825 cg09678349 cg20959907 cg21594400
ZBTB22;TAPBP;TAPBP;TAPBP;ZBTB22 ZBTB22;TAPBP;TAPBP;TAPBP;ZBTB22 ZBTB22;TAPBP;TAPBP;TAPBP;ZBTB22 ZBTB22;TAPBP;TAPBP;TAPBP;ZBTB22 ZBTB22;TAPBP;TAPBP;TAPBP;ZBTB22 ZBTB22;TAPBP;TAPBP;TAPBP;ZBTB22 ZBTB22;TAPBP;TAPBP;TAPBP;ZBTB22 ZBTB22;TAPBP;TAPBP;TAPBP;ZBTB22 ZBTB22;TAPBP;TAPBP;TAPBP;ZBTB22 ZBTB22;TAPBP;TAPBP;TAPBP;ZBTB22 ZBTB22;TAPBP;TAPBP;TAPBP;ZBTB22 ZBTB22;TAPBP;TAPBP;TAPBP;ZBTB22 APOB

APOB

APOB

APOB

APOB

APOB

APOB

APOB

APOB

APOB

COLEC11;COLEC11

COLEC11;COLEC11

COLEC11;COLEC11

COLEC11;COLEC11

COLEC11;COLEC11;COLEC11;COLEC11

COLEC11;COLEC11;COLEC11;COLEC11 ALOX12P2

ALOX12P2

ALOX12P2

ALOX12P2

ALOX12P2

ALOX12P2

DOCK4

DOCK4

DOCK4

DOCK4
NA
NA
NA
NA
NA
NA
NA
NA
NA
NA
NA
NA

rs17240441, rs577584 rs201371756, rs62122515 rs512535

rs515135, rs1367117

rs515135, rs17240441

rs60403635, rs7575840

rs60403635, rs7575840

rs6548010, rs515135

rs6548011, rs515135

rs6548011, rs515135

rs2071639

rs2071639

rs2071639

rs2071639

rs2071639

rs2071639

NA

NA

NA

NA

NA

NA

NA

NA

NA

NA 
chr6:32145383-32146595 chr6:32145383-32146595 chr6:32145383-32146595 chr6:32145383-32146595 chr6:32145383-32146595 chr6:32145383-32146595 chr6:32145383-32146595 chr6:32145383-32146595 chr6:32145383-32146595 chr6:32145383-32146595 chr6:32145383-32146595 chr6:32145383-32146595 chr6:32145383-32146595 chr6:32145383-32146595 chr6:32145383-32146595 chr6:32145383-32146595 chr6:32145383-32146595 chr6:32145383-32146595 chr6:32145383-32146595 chr6:32145383-32146595 chr6:32145383-32146595 chr6:32145383-32146595 chr6:32145383-32146595 chr6:32145383-32146595 chr6:32145383-32146595 chr6:32145383-32146595 chr6:32145383-32146595 chr7:158749953-158751591 chr7:158749953-158751591 chr7:158749953-158751591 chr7:158749953-158751591 chr7:158749953-158751591 chr7:158749953-158751591 chr7:158749953-158751591 chr7:158749953-158751591 chr6:33280149-33280436 chr6:33280149-33280436 chr6:33280149-33280436 $\operatorname{cg} 02973270$ $\operatorname{cg} 06570818$ $\operatorname{cg} 07482220$ cg09043226 cg10023837 cg11043450 cg27370696 cg08049198 cg18191873 cg18928683 cg23464264 cg25733934 cg24425483 cg11995506 cg01074928 cg02260340 cg03237964 $\operatorname{cg} 03718284$ cg08450897 cg09301199 cg13763617 cg14771938 cg20008357 cg22673001 cg01052103 cg01466825 cg15982308 cg00538212 cg00815399 cg12744031 cg00413089 cg10079374 cg11945929 cg12954512 cg13472359 cg01253676 cg02863594 cg11796996
AGPAT1;RNF5;RNF5P1

NA

AGPAT1;RNF5;RNF5P1

AGPAT1;RNF5;RNF5P1

AGPAT1;RNF5;RNF5P1

AGPAT1;RNF5;RNF5P1

AGPAT1;RNF5;RNF5P1

AGPAT1;RNF5;RNF5P1

AGPAT1;RNF5P1;RNF5

AGPAT1;RNF5P1;RNF5

AGPAT1;RNF5P1;RNF5

AGPAT1;RNF5P1;RNF5

AGPAT1;RNF5P1;RNF5

RNF5;AGPAT1;RNF5;RNF5P1

RNF5;AGPAT1;RNF5P1;RNF5

RNF5P1;RNF5;AGPAT1

RNF5P1;RNF5;AGPAT1

RNF5P1;RNF5;AGPAT1

RNF5P1;RNF5;AGPAT1

RNF5P1;RNF5;AGPAT1

RNF5P1;RNF5;AGPAT1

RNF5P1;RNF5;AGPAT1

RNF5P1;RNF5;AGPAT1

RNF5P1;RNF5;AGPAT1

RNF5P1;RNF5;AGPAT1

RNF5P1;RNF5;AGPAT1;AGPAT1

RNF5P1;RNF5;AGPAT1;AGPAT1

RNF5P1;RNF5;AGPAT1;AGPAT1

TAPBP;ТAPBP;ТAPBP

TAPBP;ТAPBP;TAPBP

TAPBP;TAPBP;TAPBP
NA

NA

NA

NA

NA

NA

NA

NA

NA

NA

NA

NA

NA

NA

NA

NA

NA

NA

NA

NA

NA

NA

NA

NA

NA

NA

NA

NA

NA

rs35143397

rs35143397

rs35143397

rs35143397

rs61693740

NA

NA

NA 


\begin{tabular}{|c|c|c|}
\hline 10 & chr6:33280149-33280436 & $\operatorname{cg} 12589538$ \\
\hline 10 & chr6:33280149-33280436 & $\operatorname{cg} 13638257$ \\
\hline 10 & chr6:33280149-33280436 & $\operatorname{cg} 14419102$ \\
\hline 10 & chr6:33280149-33280436 & $\operatorname{cg} 18353226$ \\
\hline 10 & chr6:33280149-33280436 & cg20998791 \\
\hline 10 & chr6:33280149-33280436 & $\operatorname{cg} 26083458$ \\
\hline 11 & chr6:31867757-31868169 & $\operatorname{cg} 00058449$ \\
\hline 11 & chr6:31867757-31868169 & $\operatorname{cg} 00805874$ \\
\hline 11 & chr6:31867757-31868169 & $\operatorname{cg} 00889295$ \\
\hline 11 & chr6:31867757-31868169 & $\operatorname{cg} 04603811$ \\
\hline 11 & chr6:31867757-31868169 & $\operatorname{cg} 05680710$ \\
\hline 11 & chr6:31867757-31868169 & $\operatorname{cg} 06636203$ \\
\hline 11 & chr6:31867757-31868169 & $\operatorname{cg} 07249939$ \\
\hline 11 & chr6:31867757-31868169 & $\operatorname{cg} 07910050$ \\
\hline 11 & chr6:31867757-31868169 & $\operatorname{cg} 09788778$ \\
\hline 11 & chr6:31867757-31868169 & $\operatorname{cg} 11645762$ \\
\hline 11 & chr6:31867757-31868169 & $\operatorname{cg} 12484688$ \\
\hline 11 & chr6:31867757-31868169 & $\operatorname{cg} 13127825$ \\
\hline 11 & chr6:31867757-31868169 & $\operatorname{cg} 14562426$ \\
\hline 11 & chr6:31867757-31868169 & $\operatorname{cg} 17243044$ \\
\hline 11 & chr6:31867757-31868169 & $\operatorname{cg} 17766150$ \\
\hline 11 & chr6:31867757-31868169 & $\operatorname{cg} 25013586$ \\
\hline 11 & chr6:31867757-31868169 & $\operatorname{cg} 25110523$ \\
\hline 11 & chr6:31867757-31868169 & $\operatorname{cg} 25470384$ \\
\hline 11 & chr6:31867757-31868169 & $\operatorname{cg} 25861453$ \\
\hline 12 & chr4:147164778-147165097 & $\operatorname{cg} 01539483$ \\
\hline 12 & chr4:147164778-147165097 & $\operatorname{cg} 04181032$ \\
\hline 12 & chr4:147164778-147165097 & $\operatorname{cg} 07701757$ \\
\hline 12 & chr4:147164778-147165097 & $\operatorname{cg} 07973709$ \\
\hline 13 & chr1:11714218-11714254 & $\operatorname{cg} 01420388$ \\
\hline 13 & chr1:11714218-11714254 & $\operatorname{cg} 05796704$ \\
\hline 13 & chr1:11714218-11714254 & $\operatorname{cg} 22697136$ \\
\hline
\end{tabular}

\section{TAPBP;ТAPBP;ТAPBP \\ TAPBP;TAPBP;TAPBP \\ TAPBP;TAPBP;TAPBP \\ TAPBP;TAPBP;TAPBP \\ TAPBP;TAPBP;ТAPBP \\ TAPBP;TAPBP;TAPBP \\ ZBTB12 \\ ZBTB12}

ZBTB12

ZBTB12

ZBTB12

ZBTB12

ZBTB12

ZBTB12

ZBTB12

ZBTB12

ZBTB12

ZBTB12

ZBTB12

ZBTB12

ZBTB12

ZBTB12

ZBTB12

ZBTB12

ZBTB12

$-$

$-$

$-$

FBXO44;FBXO2;FBXO44;FBXO44;FBXO44 FBXO44;FBXO2;FBXO44;FBXO44;FBXO44 FBXO44;FBXO2;FBXO44;FBXO44;FBXO44
NA

NA

NA

NA

NA

NA

NA

NA

NA

NA

NA

NA

NA

NA

NA

NA

NA

NA

NA

NA

NA

NA

NA

NA

NA

NA

NA

NA

NA

rs4478814

rs4478814

rs909934

Note. $\mathrm{Chr}=$ chromosome; DNAm $=$ DNA methylation; $\mathrm{NA}=$ not available (mQTL not identified at the $\mathrm{CpG}$ site) 
ST7.Associations between maternal sensitivity and DNA methylation at significant regions after adjustments for maternal education and psychopathology

\begin{tabular}{|c|c|c|c|c|c|c|}
\hline \multirow[b]{2}{*}{ Location } & \multirow[b]{2}{*}{ Gene(s) } & \multicolumn{2}{|c|}{$\begin{array}{c}\text { Restricted } \\
\text { unadjusted model }\end{array}$} & \multicolumn{2}{|c|}{$\begin{array}{c}\text { Restricted } \\
\text { adjusted model }\end{array}$} & \multirow[b]{2}{*}{$\%$ estimate change } \\
\hline & & estimate & SE & estimate & SE & \\
\hline chr2:241458886-241460002 & $A N K M Y 1$ & -0.149 & 0.032 & -0.149 & 0.033 & $0.00 \%$ \\
\hline chr6:30039027-30039600 & RNF39 & -0.058 & 0.017 & -0.059 & 0.018 & $1.72 \%$ \\
\hline chr6:33282879-33283184 & ZВTB22; TAPBP & -0.140 & 0.032 & -0.132 & 0.033 & $-5.71 \%$ \\
\hline chr2:21266727-21267334 & $A P O B$ & -0.150 & 0.04 & -0.119 & 0.041 & $-20.67 \%$ \\
\hline chr2:3642629-3642867 & COLEC11 & -0.202 & 0.074 & -0.196 & 0.076 & $-2.97 \%$ \\
\hline chr17:6797034-6797771 & $A L O X 12 P 2$ & -0.146 & 0.035 & -0.146 & 0.036 & $0.00 \%$ \\
\hline chr7:111368367-111368847 & DOCK4 & -0.576 & 0.071 & -0.569 & 0.073 & $-1.22 \%$ \\
\hline chr6:32145383-32146595 & RNF5P1; RNF5; AGPAT1 & 0.007 & 0.004 & 0.004 & 0.004 & $-42.86 \%$ \\
\hline chr7:158749953-158751591 & Non-annotated region & 0.079 & 0.028 & 0.087 & 0.028 & $10.13 \%$ \\
\hline chr6:33280149-33280436 & TAPBP & -0.133 & 0.039 & -0.15 & 0.04 & $12.78 \%$ \\
\hline chr6:31867757-31868169 & ZBTB12 & -0.012 & 0.005 & -0.009 & 0.005 & $-25.00 \%$ \\
\hline chr4:147164778-147165097 & Non-annotated & 0.444 & 0.079 & 0.451 & 0.081 & $1.58 \%$ \\
\hline chr1:11714218-11714254 & FBXO44; FBXO2 & -0.051 & 0.021 & -0.046 & 0.022 & $-9.80 \%$ \\
\hline
\end{tabular}

Note. $\mathrm{Chr}=$ chromosome; $\mathrm{SE}=$ standard error $; \%=$ percent 
ST8. Associations between maternal sensitivity and DNA methylation at significant regions after adjustments for DNAm at birth

\begin{tabular}{|c|c|c|c|c|c|c|}
\hline \multirow[b]{2}{*}{ Location } & & \multicolumn{2}{|c|}{$\begin{array}{c}\text { Restricted unadjusted } \\
\text { model }\end{array}$} & \multicolumn{2}{|c|}{$\begin{array}{c}\text { Restricted adjusted } \\
\text { model }\end{array}$} & \multirow[b]{2}{*}{$\begin{array}{c}\text { \% estimate } \\
\text { change }\end{array}$} \\
\hline & & estimate & SE & estimate & SE & \\
\hline chr2:241458886-241460002 & ANKMY1 & -0.134 & 0.032 & -0.079 & 0.027 & -0.41 \\
\hline chr6:30039027-30039600 & RNF39 & -0.057 & 0.017 & -0.002 & 0.013 & -97.11 \\
\hline chr6:33282879-33283184 & ZВТВ22; ТАРВP & -0.141 & 0.032 & -0.111 & 0.032 & -21.68 \\
\hline chr2:21266727-21267334 & $A P O B$ & -0.156 & 0.040 & -0.047 & 0.033 & -69.66 \\
\hline chr2:3642629-3642867 & COLEC11 & -0.176 & 0.074 & -0.070 & 0.050 & -60.33 \\
\hline chr17:6797034-6797771 & $A L O X 12 P 2$ & -0.173 & 0.034 & -0.057 & 0.024 & -67.02 \\
\hline chr7:111368367-111368847 & DOCK4 & -0.507 & 0.071 & -0.284 & 0.059 & -44.04 \\
\hline chr6:32145383-32146595 & RNF5P1; RNF5; AGPAT1 & 0.007 & 0.004 & 0.001 & 0.004 & -80.25 \\
\hline chr7:158749953-158751591 & Non-annotated region & 0.077 & 0.027 & 0.090 & 0.024 & 16.97 \\
\hline chr6:33280149-33280436 & TAPBP & -0.177 & 0.039 & -0.033 & 0.027 & -81.17 \\
\hline chr6:31867757-31868169 & ZBTB12 & -0.011 & 0.005 & -0.012 & 0.005 & 5.32 \\
\hline chr4:147164778-147165097 & Non-annotated & 0.419 & 0.080 & 0.227 & 0.063 & -45.89 \\
\hline chr1:11714218-11714254 & FBXO44; FBXO2 & -0.055 & 0.021 & -0.061 & 0.020 & 9.62 \\
\hline
\end{tabular}

Note. Chr $=$ chromosome; $\mathrm{SE}=$ standard error; $\%=$ percent 
ST9 Correlations of methylation values at birth with age 6 at significant regions

\begin{tabular}{|c|c|c|c|c|c|c|c|}
\hline Location & Gene(s) & Min. & 1st.Qu. & Median & Mean & 3rd.Qu. & Max. \\
\hline chr2:241458886-241460002 & $A N K M Y 1$ & 0.36 & 0.52 & 0.60 & 0.59 & 0.68 & 0.78 \\
\hline chr6:30039027-30039600 & RNF39 & 0.22 & 0.32 & 0.37 & 0.39 & 0.45 & 0.55 \\
\hline chr6:33282879-33283184 & ZBTB22; TAPBP & 0.22 & 0.45 & 0.56 & 0.51 & 0.60 & 0.81 \\
\hline chr2:21266727-21267334 & $A P O B$ & 0.57 & 0.69 & 0.72 & 0.71 & 0.75 & 0.78 \\
\hline chr2:3642629-3642867 & COLEC11 & 0.63 & 0.72 & 0.77 & 0.76 & 0.82 & 0.83 \\
\hline chr17:6797034-6797771 & $A L O X 12 P 2$ & 0.51 & 0.58 & 0.67 & 0.64 & 0.71 & 0.75 \\
\hline chr7:111368367-111368847 & DOCK4 & 0.48 & 0.52 & 0.57 & 0.59 & 0.63 & 0.72 \\
\hline chr6:32145383-32146595 & RNF5P1; RNF5; AGPAT1 & $\overline{0 .} 01$ & 0.12 & 0.15 & 0.16 & 0.21 & 0.32 \\
\hline chr7:158749953-158751591 & Non-annotated region & 0.48 & 0.89 & 0.93 & 0.86 & 0.94 & 0.94 \\
\hline chr6:33280149-33280436 & TAPBP & 0.46 & 0.52 & 0.56 & 0.60 & 0.63 & 0.81 \\
\hline chr6:31867757-31868169 & ZBTB12 & $\overline{-} 03$ & 0.07 & 0.11 & 0.11 & 0.17 & 0.23 \\
\hline chr4:147164778-147165097 & Non-annotated & 0.47 & 0.51 & 0.58 & 0.58 & 0.65 & 0.67 \\
\hline chr1:11714218-11714254 & FBXO44; FBXO2 & 0.31 & 0.34 & 0.37 & 0.37 & 0.40 & 0.44 \\
\hline
\end{tabular}

Note . $\mathrm{Chr}=$ chromosome; $\min .=$ minimum; 1 st Qu. = 1st quartile; 3rd. Qu. = 3rd quartile; $\max =$ maximum 


\begin{tabular}{|c|c|c|c|}
\hline ID & Name & OR & GenesinPathwayandTestList \\
\hline GO:0019005 & SCF ubiquitin ligase complex & 1.18 & FBXO2;FBXO44 \\
\hline GO:0030433 & ER-associated ubiquitin-dependent protein catabolic process & 1.18 & FBXO2;RNF5 \\
\hline GO:0034379 & very-low-density lipoprotein particle assembly & 1.09 & APOB \\
\hline GO:0034383 & low-density lipoprotein particle clearance & 1.09 & APOB \\
\hline GO:0003841 & 1-acylglycerol-3-phosphate O-acyltransferase activity & 1.09 & AGPAT1 \\
\hline GO:0034374 & low-density lipoprotein particle remodeling & 1.09 & APOB \\
\hline GO:0006516 & glycoprotein catabolic process & 1.09 & FBXO2 \\
\hline GO:0071379 & cellular response to prostaglandin stimulus & 1.09 & APOB \\
\hline GO:0031904 & endosome lumen & 1.09 & APOB \\
\hline GO:0016024 & CDP-diacylglycerol biosynthetic process & 1.09 & AGPAT1 \\
\hline GO:0042627 & chylomicron & 1.09 & APOB \\
\hline GO:0017127 & cholesterol transporter activity & 1.09 & APOB \\
\hline GO:0034362 & low-density lipoprotein particle & 1.09 & APOB \\
\hline GO:0050750 & low-density lipoprotein particle receptor binding & 1.09 & APOB \\
\hline GO:0010885 & regulation of cholesterol storage & 1.09 & APOB \\
\hline GO:0045540 & regulation of cholesterol biosynthetic process & 1.09 & APOB \\
\hline GO:0010744 & positive regulation of macrophage derived foam cell differentiation & 1.09 & APOB \\
\hline GO:0042953 & lipoprotein transport & 1.09 & APOB \\
\hline GO:0030675 & Rac GTPase activator activity & 1.09 & DOCK4 \\
\hline GO:0042887 & amide transmembrane transporter activity & 1.09 & TAPBP \\
\hline GO:0042288 & MHC class I protein binding & 1.08 & TAPBP \\
\hline GO:0005537 & mannose binding & 1.09 & COLEC11 \\
\hline GO:0031146 & SCF-dependent proteasomal ubiquitin-dependent protein catabolic process & 1.09 & FBXO2 \\
\hline GO:0071682 & endocytic vesicle lumen & 1.09 & APOB \\
\hline GO:0010884 & positive regulation of lipid storage & 1.09 & APOB \\
\hline GO:0019433 & triglyceride catabolic process & 1.09 & APOB \\
\hline GO:0001961 & positive regulation of cytokine-mediated signaling pathway & 1.09 & AGPAT1 \\
\hline GO:0006641 & triglyceride metabolic process & 1.18 & APOB;AGPAT1 \\
\hline GO:0048365 & Rac GTPase binding & 1.08 & DOCK4 \\
\hline GO:0032420 & stereocilium & 1.08 & DOCK4 \\
\hline GO:0006890 & retrograde vesicle-mediated transport & 1.08 & TAPBP \\
\hline GO:0033344 & cholesterol efflux & 1.09 & APOB \\
\hline GO:0042605 & peptide antigen binding & 1.08 & TAPBP \\
\hline GO:0070534 & protein K63-linked ubiquitination & 1.09 & RNF5 \\
\hline GO:0001540 & beta-amyloid binding & 1.08 & FBXO2 \\
\hline
\end{tabular}




\begin{tabular}{|c|c|c|c|}
\hline GO:0030669 & clathrin-coated endocytic vesicle membrane & 1.09 & APOB \\
\hline GO:0098553 & lumenal side of endoplasmic reticulum membrane & 1.08 & TAPBP \\
\hline GO:0098576 & lumenal side of membrane & 1.08 & TAPBP \\
\hline GO:0071556 & integral component of lumenal side of endoplasmic reticulum membrane & 1.08 & TAPBP \\
\hline GO:0032855 & positive regulation of Rac GTPase activity & 1.08 & DOCK4 \\
\hline GO:0030163 & protein catabolic process & 1.36 & FBXO2;FBXO44;APOB;RNF5 \\
\hline GO:0030317 & sperm motility & 1.09 & APOB \\
\hline GO:0030971 & receptor tyrosine kinase binding & 1.08 & DOCK4 \\
\hline GO:0070936 & protein K48-linked ubiquitination & 1.08 & RNF5 \\
\hline GO:0042277 & peptide binding & 1.17 & FBXO2;TAPBP \\
\hline GO:0048844 & artery morphogenesis & 1.08 & APOB \\
\hline GO:0030246 & carbohydrate binding & 1.17 & FBXO2;COLEC11 \\
\hline GO:0005789 & endoplasmic reticulum membrane & 1.33 & APOB;TAPBP;AGPAT1;RNF5 \\
\hline GO:0042158 & lipoprotein biosynthetic process & 1.08 & APOB \\
\hline GO:0001948 & glycoprotein binding & 1.08 & FBXO2 \\
\hline GO:0015833 & peptide transport & 1.08 & TAPBP \\
\hline GO:0002479 & antigen processing and presentation of exogenous peptide antigen via MHC class I & 1.08 & TAPBP \\
\hline GO:0071356 & cellular response to tumor necrosis factor & 1.08 & APOB \\
\hline GO:0006518 & peptide metabolic process & 1.08 & TAPBP \\
\hline GO:0051082 & unfolded protein binding & 1.08 & TAPBP \\
\hline GO:0005581 & collagen & 1.08 & COLEC11 \\
\hline GO:0030165 & PDZ domain binding & 1.08 & DOCK4 \\
\hline GO:0042626 & ATPase activity & 1.08 & TAPBP \\
\hline GO:0044309 & neuron spine & 1.08 & FBXO2 \\
\hline GO:0043197 & dendritic spine & 1.08 & FBXO2 \\
\hline GO:0009791 & post-embryonic development & 1.08 & APOB \\
\hline GO:0017124 & SH3 domain binding & 1.08 & DOCK4 \\
\hline GO:0060326 & cell chemotaxis & 1.08 & DOCK4 \\
\hline
\end{tabular}

Note. $\mathrm{GO}=$ gene ontology; $\mathrm{OR}=$ odd ratio; $\mathrm{p}=\mathrm{p}$-value. Pathways highlighted in green were validated by MissMethyl. 
ST11. BECon Brain-Blood Correlations

\begin{tabular}{|c|c|c|c|c|c|c|c|}
\hline Region & Location & CpG & Genes & Cor.Blood.BA7 & Cor.Blood.BA10 & Cor.Blood.BA20 & Cor.>.average \\
\hline 1 & $\begin{array}{c}\text { chr2:241458886- } \\
241460002\end{array}$ & $\operatorname{cg} 03743720$ & ANKMY1 & 0.28 & 0.4 & 0.16 & No \\
\hline 1 & $\begin{array}{c}\text { chr2:241458886- } \\
241460002\end{array}$ & $\operatorname{cg} 05371791$ & ANKMY1 & 0.38 & 0.27 & 0.26 & BA7 \\
\hline 1 & $\begin{array}{c}\text { chr2:241458886- } \\
241460002\end{array}$ & $\operatorname{cg} 06476685$ & ANKMY1 & 0.34 & 0.36 & 0.12 & No \\
\hline 1 & $\begin{array}{c}\text { chr2: } 241458886- \\
241460002\end{array}$ & $\operatorname{cg} 08276645$ & ANKMY1 & 0.47 & 0.51 & 0.21 & BA7, BA10 \\
\hline 1 & $\begin{array}{c}\text { chr2:241458886- } \\
241460002\end{array}$ & $\operatorname{cg} 08461339$ & ANKMY1 & 0.19 & 0.22 & -0.04 & No \\
\hline 1 & $\begin{array}{c}\text { chr2:241458886- } \\
241460002\end{array}$ & $\operatorname{cg} 16909733$ & ANKMY1 & 0.49 & 0.33 & 0.22 & BA7 \\
\hline 1 & $\begin{array}{c}\text { chr2:241458886- } \\
241460002\end{array}$ & $\operatorname{cg} 24086040$ & ANKMY1 & 0.5 & 0.4 & 0.07 & BA7 \\
\hline 1 & $\begin{array}{c}\text { chr2:241458886- } \\
241460002\end{array}$ & $\operatorname{cg} 24539848$ & ANKMY1 & 0.22 & -0.01 & -0.15 & No \\
\hline 2 & chr6:30039027-30039600 & $\operatorname{cg} 00947782$ & RNF39 & 0.12 & 0.06 & 0.53 & BA20 \\
\hline 2 & chr6:30039027-30039600 & $\operatorname{cg} 02188185$ & RNF39 & -0.09 & 0.04 & 0 & No \\
\hline 2 & chr6:30039027-30039600 & $\operatorname{cg} 03343571$ & RNF39 & 0.69 & 0.28 & 0.68 & BA7, BA20 \\
\hline 2 & chr6:30039027-30039600 & $\operatorname{cg} 05563515$ & RNF39 & 0.34 & 0.36 & 0.44 & BA20 \\
\hline 2 & chr6:30039027-30039600 & $\operatorname{cg} 06249604$ & RNF39 & 0.22 & 0.27 & 0.68 & BA20 \\
\hline 2 & chr6:30039027-30039600 & $\operatorname{cg} 07179033$ & RNF39 & 0.34 & 0.25 & 0.57 & BA20 \\
\hline 2 & chr6:30039027-30039600 & $\operatorname{cg} 07382347$ & RNF39 & 0.28 & 0.2 & 0.76 & BA20 \\
\hline 2 & chr6:30039027-30039600 & $\operatorname{cg} 08491487$ & RNF39 & 0.15 & 0.01 & 0.33 & No \\
\hline 2 & chr6:30039027-30039600 & cg09279736 & RNF39 & 0.39 & 0.37 & 0.69 & BA7, BA20 \\
\hline 2 & chr6:30039027-30039600 & $\operatorname{cg} 10568066$ & RNF39 & 0.45 & 0.46 & 0.75 & $\begin{array}{l}\text { BA7, BA10, } \\
\text { BA20 }\end{array}$ \\
\hline 2 & chr6:30039027-30039600 & $\operatorname{cg} 10930308$ & RNF39 & 0.24 & 0.46 & 0.51 & BA10, BA20 \\
\hline 2 & chr6:30039027-30039600 & $\operatorname{cg} 12633154$ & RNF39 & 0.2 & 0.41 & 0.64 & $\mathrm{BA} 10, \mathrm{BA} 20$ \\
\hline 2 & chr6:30039027-30039600 & $\operatorname{cg} 13185413$ & RNF39 & 0.42 & 0.26 & 0.59 & BA7, BA20 \\
\hline 2 & chr6:30039027-30039600 & $\operatorname{cg} 13401893$ & RNF39 & 0.1 & 0.31 & 0.74 & BA20 \\
\hline 2 & chr6:30039027-30039600 & $\operatorname{cg} 13918754$ & RNF39 & 0.24 & -0.32 & -0.03 & No \\
\hline 2 & chr6:30039027-30039600 & $\operatorname{cg} 15877520$ & RNF39 & 0.07 & -0.28 & 0.41 & BA20 \\
\hline 2 & chr6:30039027-30039600 & $\operatorname{cg} 16078649$ & RNF39 & -0.2 & 0.37 & 0.59 & BA20 \\
\hline 2 & chr6:30039027-30039600 & $\operatorname{cg} 18930910$ & RNF39 & 0.51 & -0.18 & 0.5 & BA7, BA20 \\
\hline 2 & chr6:30039027-30039600 & cg20249327 & RNF39 & 0.43 & 0.13 & 0.05 & BA7 \\
\hline 2 & chr6:30039027-30039600 & $\operatorname{cg} 23712018$ & RNF39 & 0.09 & 0.04 & 0.61 & BA20 \\
\hline 2 & chr6:30039027-30039600 & $\operatorname{cg} 26730543$ & RNF39 & 0.26 & 0.43 & 0.21 & BA10 \\
\hline
\end{tabular}


chr6:33282879-33283184 chr6:33282879-33283184 chr6:33282879-33283184 chr6:33282879-33283184 chr6:33282879-33283184 chr6:33282879-33283184 chr6:33282879-33283184 chr6:33282879-33283184 chr6:33282879-33283184 chr6:33282879-33283184 chr6:33282879-33283184 chr6:33282879-33283184 chr6:33282879-33283184 chr6:33282879-33283184 chr6:33282879-33283184 chr2:21266727-21267334 chr2:21266727-21267334 chr2:21266727-21267334 chr2:21266727-21267334 chr2:21266727-21267334 chr2:21266727-21267334 chr2:21266727-21267334 chr2:21266727-21267334 chr2:21266727-21267334 chr2:21266727-21267334 chr2:3642629-3642867 chr2:3642629-3642867 chr2:3642629-3642867 chr2:3642629-3642867 chr2:3642629-3642867 chr2:3642629-3642867 chr17:6797034-6797771 chr17:6797034-6797771 chr17:6797034-6797771 chr17:6797034-6797771 chr17:6797034-6797771 chr17:6797034-6797771 chr7:111368367- cg03000593 cg05210804 cg07245868 cg07895437 $\operatorname{cg} 08771019$ cg10134527 cg11917542 cg13027595 cg14309283 cg14473643 cg17055704 cg18144560 cg25954512 cg26646118 cg27168291 cg00673290 cg03350299 cg07636176 cg15246511 cg16306978 cg16723488 cg24309555 cg25071744 cg25123895 cg26112457 cg00835279 cg09974661 cg16430428 cg17872886 cg19867917 cg26615126 cg01758314 $\operatorname{cg} 07391831$ $\operatorname{cg} 09705592$ cg16893174 $\operatorname{cg} 18007837$ cg26334670 cg01567825

$\begin{array}{cc}\text { ZBTB22, TAPBP } & -0.14 \\ \text { ZBTB22, TAPBP } & 0.4 \\ \text { ZBTB22, TAPBP } & 0.34 \\ \text { ZBTB22, TAPBP } & 0.54 \\ \text { ZBTB22, TAPBP } & -0.04 \\ \text { ZBTB22, TAPBP } & 0.26 \\ \text { ZBTB22, TAPBP } & -0.09 \\ \text { ZBTB22, TAPBP } & -0.21 \\ \text { ZBTB22, TAPBP } & 0.12 \\ \text { ZBTB22, TAPBP } & 0.27 \\ \text { ZBTB22, TAPBP } & 0.54 \\ \text { ZBTB22, TAPBP } & 0.33 \\ \text { ZBTB22, TAPBP } & -0.06 \\ \text { ZBTB22, TAPBP } & -0.15 \\ \text { ZBTB22, TAPBP } & 0.24 \\ \text { APOB } & 0.19 \\ \text { APOB } & 0.39 \\ \text { APOB } & 0.21 \\ \text { APOB } & 0.04 \\ \text { APOB } & 0.09 \\ \text { APOB } & 0.31 \\ \text { APOB } & 0.59 \\ \text { APOB } & -0.19 \\ \text { APOB } & 0.15 \\ \text { APOB } & -0.07 \\ \text { COLEC11 } & 0.45 \\ \text { COLEC11 } & 0.49 \\ \text { COLEC11 } & 0.45 \\ \text { COLEC11 } & 0.35 \\ \text { COLEC11 } & 0.68 \\ \text { COLEC11 } & 0.57 \\ \text { ALOX12P2 } & 0.53 \\ \text { ALOX12P2 } & -0.29 \\ \text { ALOX12P2 } & -0.05 \\ \text { ALOX12P2 } & -0.09 \\ \text { ALOX12P2 } & -0.33 \\ \text { ALOX12P2 } & 0.46 \\ \text { DOCK4 } & -15\end{array}$

$\begin{array}{ccc}0.11 & -0.25 & \text { No } \\ 0.61 & 0.17 & \text { BA7, BA10 } \\ 0.15 & -0.05 & \text { No } \\ 0.6 & 0.17 & \text { BA7, BA10 } \\ 0.47 & 0.12 & \text { BA10 } \\ -0.14 & -0.06 & \text { No } \\ 0.31 & -0.27 & \text { No } \\ -0.07 & -0.24 & \text { No } \\ 0.46 & -0.09 & \text { BA10 } \\ 0.51 & 0.03 & \text { BA10 } \\ 0.51 & 0.04 & \text { BA7, BA10 } \\ 0.44 & -0.02 & \text { BA10 } \\ -0.09 & -0.22 & \text { No } \\ 0.14 & -0.1 & \text { No } \\ 0.04 & -0.18 & \text { No } \\ 0.18 & 0.17 & \text { No } \\ 0.06 & 0.03 & \text { BA7 } \\ 0.14 & 0.23 & \text { No } \\ 0.2 & -0.18 & \text { No } \\ -0.22 & -0.14 & \text { No } \\ -0.08 & -0.04 & \text { No } \\ 0.09 & -0.15 & \text { BA7 } \\ 0.03 & -0.03 & \text { No } \\ 0.43 & 0.2 & \text { BA10 } \\ -0.21 & 0.06 & \text { No } \\ 0.42 & -0.02 & \text { BA7, BA10 } \\ 0.41 & 0.23 & \text { BA7, BA10 } \\ 0.26 & -0.22 & \text { BA7 } \\ 0.37 & 0.32 & \text { No } \\ 0.36 & 0.18 & \text { BA7 } \\ 0.39 & 0.41 & \text { BA10 } \\ 0.1 & -0.03 & \text { BA7 } \\ 0.23 & 0.09 & \text { No } \\ -0.13 & -0.01 & \text { No } \\ -0.21 & 0.02 & \\ -0.39 & 0.29 & \\ -0.1 & 0.05 & \\ -0.45 & & \\ & & \end{array}$


111368847

chr7:111368367-

111368847

chr7:111368367-

111368847

chr7:111368367-

111368847

chr6:32145383-32146595

chr6:32145383-32146595

chr6:32145383-32146595 chr6:32145383-32146595 chr6:32145383-32146595 chr6:32145383-32146595 chr6:32145383-32146595 chr6:32145383-32146595 chr6:32145383-32146595 chr6:32145383-32146595 chr6:32145383-32146595 chr6:32145383-32146595 chr6:32145383-32146595 chr6:32145383-32146595 chr6:32145383-32146595 chr6:32145383-32146595 chr6:32145383-32146595 chr6:32145383-32146595 chr6:32145383-32146595 chr6:32145383-32146595 chr6:32145383-32146595 chr6:32145383-32146595 chr6:32145383-32146595 chr6:32145383-32146595 chr6:32145383-32146595 chr6:32145383-32146595 chr7:158749953158751591 chr7:158749953158751591 chr7:158749953- cg09678349

$\operatorname{cg} 20959907$

DOCK4

$-0.31$

DOCK4

$-0.21$

DOCK4

$-0.36$

$-0.24$

$\operatorname{cg} 01052103$

$\operatorname{cg} 01074928$

$\operatorname{cg} 01466825$

cg02260340

cg02973270

$\operatorname{cg} 03237964$

$\operatorname{cg} 03718284$

$\operatorname{cg} 06570818$

cg07482220

$\operatorname{cg} 08049198$

cg08450897

cg09043226

$\operatorname{cg} 09301199$

$\operatorname{cg} 10023837$

cg11043450

cg11995506

$\operatorname{cg} 13763617$

cg14771938

cg15982308

cg18191873

cg18928683

cg20008357

$\operatorname{cg} 22673001$

cg23464264

cg25733934

cg27370696

$\operatorname{cg} 00413089$

$\operatorname{cg} 00538212$

$\operatorname{cg} 00815399$
AGPAT1, RNF5, RNF5P1, AGPAT1

AGPAT1, RNF5, RNF5P1

RNF5, RNF5P1, AGPAT1

RNF5, RNF5P1, AGPAT1

RNF5, RNF5P1, AGPAT1

AGPAT1, RNF5, RNF5P1

RNF5, RNF5P1, AGPAT1

RNF5, RNF5P1, AGPAT1

RNF5, RNF5P1, AGPAT1

RNF5, RNF5P1, AGPAT1

RNF5, RNF5P1, AGPAT1

RNF5, RNF5P1, AGPAT1

RNF5, RNF5P1, AGPAT1

RNF5, RNF5P1, AGPAT1

RNF5, RNF5P1, AGPAT1

RNF5, RNF5P1, AGPAT1

RNF5, RNF5P1, AGPAT1

RNF5, RNF5P1, AGPAT1

RNF5, RNF5P1, AGPAT1

RNF5, RNF5P1, AGPAT1

RNF5, RNF5P1, AGPAT1

RNF5, RNF5P1, AGPAT1

AGPAT1, RNF5, RNF5P1

RNF5, RNF5P1, AGPAT1

RNF5, RNF5P1, AGPAT1

RNF5, RNF5P1, AGPAT1

None

None

None
0.76
$-0.25$

$-0.39$

$-0.63$

$-0.17$

$-0.14$

$-0.05$

0.38

$-0.25$

0.08

$-0.48$

0.11

$-0.36$

$-0.11$

$-0.19$

0.23

0.03

$-0.01$

0.29

0.04

$-0.58$

$-0.26$

0.02

0.09

$-0.37$

0.48

$-0.09$

$-0.38$

$-0.22$

$-0.38$

0.42

0.16

0.67
$-0.15$

$-0.18$

$-0.3$

$-0.17$

$-0.09$

$-0.06$

0.16

$-0.31$

0.19

$-0.62$

0.14

$-0.19$

0.01

$-0.36$

$-0.06$

$-0.12$

0.19

$-0.13$

$-0.04$

$-0.42$

0.18

$-0.2$

0.06

$-0.47$

0.65

$-0.37$

$-0.08$

0.05

$-0.45$

0.51

0.47

0.66
No

No

BA10

No

BA7

No

BA7

No

No

BA10, BA20

No

No

BA7

BA20

No

No

No

No

No

BA10, BA20

BA7

No

BA7

BA20

BA7, BA10,

BA20

BA20

No

No

BA7, BA20

BA7, BA10, BA20

BA20

BA7, BA10, 
158751591

BA20

chr7:158749953-

$$
158751591
$$

cg10079374

None

0.65

0.59

0.48

BA7, BA10, chr7:158749953-

$$
158751591
$$

$\operatorname{cg} 11945929$

None

0.62

0.55

0.31

BA20

chr7:158749953-

158751591

$\operatorname{cg} 12744031$

None

0.56

0.54

0.51

None

0.46

0.52

0.37

158751591

chr7:158749953-

158751591

chr6:33280149-33280436

chr6:33280149-33280436

chr6:33280149-33280436

chr6:33280149-33280436

chr6:33280149-33280436

chr6:33280149-33280436

chr6:33280149-33280436

chr6:33280149-33280436

chr6:33280149-33280436

chr6:31867757-31868169

chr6:31867757-31868169

chr6:31867757-31868169

chr6:31867757-31868169

chr6:31867757-31868169

chr6:31867757-31868169 chr4:147164778-

$$
147165097
$$

chr4:147164778-

$$
147165097
$$

chr4:147164778-

$$
147165097
$$

chr4:147164778147165097

$\operatorname{cg} 13472359$

None

0.47

$-0.18$

$-0.06$

0.13

TAPBP

0.28

cg02863594

cg11796996

cg12589538

$\operatorname{cg} 13638257$

cg14419102

cg18353226

cg20998791

cg26083458

cg00889295

cg05680710

cg07249939

cg11645762

cg14562426

cg25110523

cg01539483

TAPBP

0.14

TAPBP

0.02

TAPBP

0.21

0.01

$-0.04$

TAPBP

TAPBP

TAPBP

0.26

TAPBP

$-0.15$

TAPBP

0.14

0.54

ZBTB12

0.24

ZBTB12

$-0.01$

ZBTB12

0.81

ZBTB12

0.39

ZBTB12

$-0.07$

ZBTB12

0.14

0.18

0.23

0.12

0.19

$-0.22$

0.16

0.13

$-0.28$

0.11

0.42

0.4

$-0.3$

0.13

0.09

$-0.26$

0.27

0.22

0.36

$-0.12$

0.06

0.34

$-0.08$

0.14

0.09

0.24

0.15

0.37

0.21

0.15

0.22

0.27

0.06

$-0.01$

BA7, BA10

BA7, BA10, BA20

BA7, BA10, BA20

BA7

BA20

No

No

BA20

No

No

No

No

BA7

BA20

No

BA7, BA10

BA7

No

No

$\operatorname{cg} 04181032$

None

0.03

$-0.2$

0.18

No

None

$-0.17$

0.04

0.21

chr1:11714218-11714254

cg07973709

None

$-0.03$

FBXO2, FBXO44

cg05796704

\begin{tabular}{lll} 
chr1:11714218-11714254 & cg22697136 & FBXO2, FBXO44 \\
\hline Brodmann area; chr $=$ chromosome; cor $=$ correlation; $>$ = greater than
\end{tabular}

0.26

0.09

$-0.36$

0.23

Note. $\mathrm{BA}=$ Brodmann area; $\mathrm{chr}=$ chromosome; cor $=$ correlation; $>=$ greater than 